\title{
Influence of ionic liquid-like cationic pendants composition in cellulose based polyelectrolytes on membrane-based $\mathrm{CO}_{2}$ separation
}

\author{
Daria Nikolaeva $^{\mathrm{a}, \mathrm{b}, *}$, Katrien Verachtert ${ }^{\mathrm{a}}$, Itxaso Azcune ${ }^{\mathrm{c}}$, Johannes C. Jansen ${ }^{\mathrm{d}}$, Ivo F. \\ J. Vankelecom ${ }^{\text {a }}$ \\ ${ }^{a}$ Membrane Technology Group (MTG), cMACS, Faculty Bio-science Engineering. Celestijnenlaan 200F, 3001 Leuven, Belgium \\ ${ }^{b}$ UCLouvain - IMMC, Materials \& Process Engineering, Place Sainte Barbe 2, 1348 Louvain-la-Neuve, Belgium \\ 'Fundación CIDETEC, Paseo Miramon 196, 20014 Donostia, San Sebastian, Spain \\ ${ }^{d}$ Institute on Membrane Techrology (ITM-CNR), Via P. Bucci 17/C, 87036 Rende (CS), Italy
}

A R T I C L E I N F •

Keywords:

Cellulose acetate

Polyelectrolytes

$\mathrm{C}_{2}$ separation

Thin-film composites

Carbon capture

\begin{abstract}
A B S T R A C T
Cellulose acetate (CA) is an attractive membrane polymer for $\mathrm{CO}_{2}$ capture market. However, its low $\mathrm{CO}_{2}$ permeability hampers its application as part of a membrane for most relevant types of $\mathrm{CO}_{2}$ containing feeds. This work investigates the enhancement of CA separation performance by incorporating ionic liquid-like pendants (1methylinidazol, 1-methylpyrrolidine, and 2-hydroxyethyldimethylamine (HEDMA) on the CA backbone. These CA-based polyelectrolytes (PEs), synthesised by covalent grafting of cationic pendants with anion metathesis, were characterised by NMR, FTIR, DSC/TGA, and processed into thin-film composite membranes. The menbrane performance in $\mathrm{CO}_{2} / \mathrm{N}_{2}$ mixed-gas permeation experiments shows a decrease in $\mathrm{CO}_{2}$ and $\mathrm{N}_{2}$ permeability and an initial decrease and then gradual increase in $\mathrm{CO}_{2} / \mathrm{N}_{2}$ selectivity with increasing HEDMA content. The amount of HEDMA attached to the CA backbone determines overall separation process in bifunctional PEs. This indicates that the hydroxy-substituted cationic pendants altel interactions between PEs network and permeating $\mathrm{CO}_{2}$ molecules, suggesting possibilities for further improvements.
\end{abstract}

\section{Introduction}

Polyelectrolytes (PEs) are charge bearing polymers well-suited for membrane-based separations through their flexible chemical modifications, thermal $\left(>300^{\circ} \mathrm{C}\right.$ ), and chemical stability (Joseph, Ahmadiannamini, Hoogenboom, \& Vankelecom, 2014; Nikolaeva \& Luis, 2020; Zhang et al., 2020). Thus, PEs have already been applied in biogas and flue separation, pervaporation, nanofiltration, and other fields, and their implementation showed pronissing results (Ahmadiannamini et al., 2012; Bakonyi, Nemestóthy, \& Bélafi-Bakó, 2013; Qu et al., 2019; Rynkowska, Fatyeyeva, \& Kujawski, 2018; Teodoro, Tomé, Mantione, Mecerreyes, \& Marrucho, 2018; Vollas, Chouliaras, Deimede, Ioannides, \& Kallitsis, 2018). Nevertheless, PEs still experience some setbacks attributed to their processability, safety, and production costs (Guo et al., 2020). Since many PEs are synthesised from fossil fuel derived monomers, their large scale application in membrane-based $\mathrm{C}_{2}$ capture may raise concerns over their environmental inpact in the nearest future (Hospido \& Rodríguez, 2019; Rathnayake, Perera, \& Vidanapathirana, 2020). PEs and poly ionic liquids (PILs), particularly, have been branded as a 'greener solution' for polymer-based membrane gas separation (Gouveia, Ventaja, Tomé, \& Marrucho, 2018; M.L.L. Rathnayake et al., 2020). The term 'greener', however, mainly relies on the properties ascribed to the precursor materials (cross-linkable ionic liquids) and only if all reagents are completely recycled (Frade \& Afonso, 2010; Hospido \& Rodríguez, 2019; Maciel, Wales, Seferin, \& Sans, 2019; Zhang, Bakshi, \& Demessie, 2008).

Alternative strategies to reduce the PE's environmental inpact are seen in their minimised consumption during the membrane fabrication process. Various methods to deposit ultra-thin PEs layers have been reviewed recently (Liu, Nothling, Webley, Fu, \& Qiao, 2019; Nikolaeva \& Luis, 2020; Singh \& Savoy, 2020; Zhang et al., 2020). The material and process optimisation yielded selectivities exceeding 100 with moderate permeances of approximately $10 \mathrm{GPU}$, surpassing the Robeson upper bound for $\mathrm{CO}_{2} / \mathrm{N}_{2}$. While excellent in lab-scale testing, these PE separation parameters can limit the industrial scale $\mathrm{CO}_{2}$ separation, as higher gas fluxes are still required (Ding, 2020; Kárászová et al., 2020; Lee \& Kim, 2020; Merkel, Lin, Wei, \& Baker, 2010; Scholes, 2020).

Cellulose derivatives in the form of cellulose acetates (CA) have

\footnotetext{
* Colresponding author at: Membrane Technology Group (MTG), cMACS, Faculty Bio-science Engineering, Celestijnenlaan 200F, 3001 Leuven, Belgiun.

E-mail address: daria.nikolaeva@uclouvain.be (D. Nikolaeva).
} 
dominated the commercial market for polymer membranes over the last decades (Baker \& Lokhandwala, 2008; Basu, Khan, Cano-Odena, Liu, \& Vankelecon, 2010; Esposito et al., 2019; Galizia et al., 2017; Liskey et al., 2018; Liu et al., 2020). Their good thermal properties, characterised by moderately high glass transition and initial decomposition tenperatures, also enable CA application in processes with elevated temperatures, e.g. post-combustion $\mathrm{CO}_{2}$ capture (Lu, Kanehashi, Scholes, \& Kentish, 2016; Magnanelli, Wilhelmsen, Johannessen, \& Kjelstrup, 2016; Sundell et al., 2019). Several concepts have investigated the opportunity to boost the $\mathrm{CO}_{2}$ flux by combining $\mathrm{CA}$ with various additives, e.g. polyethyleneglycol, ionic liquids, adamantoyl chloride, cationic pendants, etc. (Chen et al., 2014; Deng et al., 2016; Lam et al., 2016; Li, Wang, Nagai, Nakagawa, \& Mau, 1998; Nikolaeva et al., 2018). While several articles report on properties and performance of CA-based polyelectrolytes, the effect of PE composition on their perfornance in membrane-based $\mathrm{CO}_{2}$ separation remains virtually unexplored (Gericke, Liebert, \& Heinze, 2009; Klemm, Heinze, \& Wagenknecht, 1996; Mazoniene, Joceviciute, Kazlauske, Niemeyer, \& Liesiene, 2011).

In this work, CA is functionalised with IL-like cationic pendants to tailor their transport properties. This polymer is subsequently processed into thin film composite (TFC) membranes by a semi-autoniated coating process. CA-based PEs and their corresponding membranes are characterised using NMR, FTIR-ATR, TGA/DSC, SEM. These membranes are then compared in terms of their efficiency in $\mathrm{CO}_{2} / \mathrm{N}_{2}$ separation. Our hypothesis states that the presence of more polar groups in the cationic pendant or the combination of several cationic pendants affects the separation performance of CA-based PEs and may facilitate their application as tailor-made PEs for $\mathrm{CO}_{2}$ separations. The scope and novelty of this work is to develop new materials via an alternative procedure that does not require the synthesis and polymerisation of polymerisable IL monomers. One of the advantages of this procedure is that it guarantees a high molar mass of the resulting polymer, since it is not critically dependent on the polymerisation reaction.

\section{Materials and methods}

\subsection{Materials}

Cellulose acetate (CA) with $39.7 \mathrm{wt} \%$ acetyl content, corresponding to the degree of substitution of 2.4, and an average $\bar{M}_{n}$ of $50 \mathrm{kDa}$ was purchased from Signa-Aldrich. CA powder was dried under vacuum at $100{ }^{\circ} \mathrm{C}$ for $48 \mathrm{~h}$ to remove the sorbed moisture prior to use. 4-Chlorobutyryl chloride (98\%) was purchased from Across Organics. N-methylimidazole (> 99\%), N-methylpyrrolidine (> 99\%), 2dimethylaminoethanol (99\%), and triethylamine (99\%) were purchased from Signa-Aldrich. Dichloromethane (99.5\%) was purchased from Scharlab. Bis(trifluoromethylsulfonyl)inide lithium salt $\left(\mathrm{LiTf}_{2} \mathrm{~N}\right)$ was purchased from IoLiTec.

Matrimid® 9725 was kindly provided by Huntsman (Switzerland) and the non-woven polypropylene/polyethylene (PP/PE) fabric Novatexx@2483 by Freudenberg (Germany). P-xylylenediamine (XDA, > 98\%) cross-linker was purchased from Fluka. N-methylpyrrolidinone (NMP, Acros, 99\%), tetrahydrofuran (THF, Acros, 99.5\%), aceton (Merck, 99.8\%), ethanol (Fisher Scientific, 99.5\%), methanol (Acros, 99.8\%), isopropanol (IPA, VWR, 99.5\%), n-hexane (Merck, 99\%) were all used without further purication. Polydimethylsiloxane (PDMS) was acquired from Momentive Performance Materials in the form of RTV615 silicone rubber compound kit (Leverkusen, Germany).

\subsection{Polyelectrolyte synthesis}

\subsubsection{Cellulose acetate-(4-chlorobutyrate) (CA-P)}

Cellulose acetate $(30 \mathrm{~g}$, glucose dimer $0.056 \mathrm{~mol})$ was dissolved completely in dry dichloromethane $(500 \mathrm{~mL})$ with consequent addition of triethylamine ( $25.5 \mathrm{~mL}, 0.183 \mathrm{~mol}$ ). The solution was cooled at $0{ }^{\circ} \mathrm{C}$ in an ice-water bath to remove excess heat of reaction, 4-chlorobutyryl chloride $(16.8 \mathrm{~mL}, 0.150 \mathrm{~mol})$ was added drop-wise, and stirred at ambient temperature for $24 \mathrm{~h}$. The reaction mixture was transferred drop-wise into a solution of ethanol/water (volume ratio 4:1, $450 \mathrm{~mL}$ ) to precipitate the polymer and to remove excess of reagents. The precipitate was collected manually, re-dissolved in acetone, and precipitated for the second time in an ethanol/water mixture (volume ratio 4:1, $450 \mathrm{~mL}$ ) and allowed to dry under reduced pressure. Yield: $29.7 \mathrm{~g}(82 \%)$ (Fig. 1).

\subsection{2. $\mathrm{Im}$}

Cellulose acetate-(4-chlorobutyrate) (CA-P) $(7.85 \mathrm{~g}, 0.0123 \mathrm{~mol})$ solution in DMF $(125 \mathrm{~mL})$ reacted with the excess of 1-methylimidazole (2.3 $\mathrm{mL}, 0.0288 \mathrm{~mol}, 2.3 \mathrm{eq}$.) at $80^{\circ} \mathrm{C}$ for $7 \mathrm{~d}$. DMF was removed from intermediate product $(\mathrm{P}[\mathrm{CA}-\mathrm{In}][\mathrm{Cl}])$ by rotavapor and the remaining solid was re-dissolved in water and purified by dialysis using a SnakeSkin $3.5 \mathrm{kDa}$ molecular weight cut off (MWCO) membrane to remove excess of 1-methylimidazole present in the starting material. $\mathrm{P}[\mathrm{CA}][\mathrm{Cl}]$ exchanged the anions with $\operatorname{LiTf}_{2} \mathrm{~N}(4.14 \mathrm{~g}, 0.0144 \mathrm{~mol}, 1.2 \mathrm{eq}$.) to yield $\mathrm{P}$ [CA-Im] $\left[\mathrm{Tf}_{2} \mathrm{~N}\right](\mathrm{Im}$, Table 1). The product was washed with water to remove $\mathrm{LiCl}$ and unreacted reagents, and then dried under vacuun at $60{ }^{\circ} \mathrm{C}$ for $24 \mathrm{~h}$. Yield: $6.1 \mathrm{~g}(52 \%)$.

\subsection{3. $P y r$}

CA-P $(13 \mathrm{~g}, 0.0203 \mathrm{~mol})$ solution in DMF $(150 \mathrm{~mL})$ reacted with the excess of $\mathrm{N}$-methylpyrrolidine $\left(6.5 \mathrm{~mL}, 0.0625 \mathrm{~mol}, 3 \mathrm{eq}\right.$ ) at $80^{\circ} \mathrm{C}$ for $3 \mathrm{~d}$. DMF was removed from the intermediate product (P[CA-Pyr] $[\mathrm{Cl}]$ ) by rotavapor and the remaining solid was re-dissolved in water and purified by dialysis using a SnakeSkin $3.5 \mathrm{kDa}$ MWCO membrane to remove the unreacted starting material. $\mathrm{P}[\mathrm{CA}-\mathrm{Pyr}][\mathrm{Cl}]$ exchanged the anions with LiTf $_{2} \mathrm{~N}\left(5.8 \mathrm{~g}, 0.0202 \mathrm{~mol}, 1.0\right.$ eq.) to yield P[CA-Pyr] $\left[\mathrm{Tf}_{2} \mathrm{~N}\right.$ ] (Pyr, Table 1). The product was washed with water to remove $\mathrm{LiCl}$ and unreacted reagents, and then dried under vacuum at $60^{\circ} \mathrm{C}$ for $24 \mathrm{~h}$. Yield: $12.0 \mathrm{~g}$ (61\%) (Nikolaeva et al., 2018).

\subsubsection{HEDMA}

CA-P $(10 \mathrm{~g}, 0.0156 \mathrm{~mol})$ solution in DMF $(125 \mathrm{~mL})$ reacted with an excess of 2-methylaminoethanol $\left(3.7 \mathrm{~mL}, 0.0368 \mathrm{~mol}, 2.3 \mathrm{eq}\right.$.) at $80^{\circ} \mathrm{C}$ for $7 \mathrm{~d}$. DMF was removed from the intermediate product (P[CAHEDMA] [Cl]) by rotavapor and the remaining solid was re-dissolved in water and purified through dialysis using a SnakeSkin $3.5 \mathrm{kDa}$ MWCO membrane to remove the unreacted starting material. P[CA-HEDMA] [Cl] exchanged anions with $\mathrm{LiTf}_{2} \mathrm{~N}$ (5.45 g, 0.019 mol, 1.2 eq.) to yield P[CA-HEDMA] $\left[\mathrm{Tf}_{2} \mathrm{~N}\right]$ (HEDMA, Table 1 ). The product was washed with water to remove $\mathrm{LiCl}$ and unreacted reagents, and then dried under vacuum at $60^{\circ} \mathrm{C}$ for $24 \mathrm{~h}$. Yield: $11.8 \mathrm{~g} \mathrm{(78 \% )}$.

\subsection{5. $\mathrm{Pyr}_{3} H E D M A_{1}$}

CA-P $(6.0 \mathrm{~g}, 0.00937 \mathrm{~mol})$ solution in DMF $(100 \mathrm{~mL})$ reacted with 2dimethylaninoethanol $(0.43 \mathrm{~mL}, 0.0044 \mathrm{~mol}, 0.4 \mathrm{eq}$. $)$ and N-methylpyrrolidine $(1.33 \mathrm{~mL}, 0.0128 \mathrm{~mol}, 1.4$ eq. $)$ at $80^{\circ} \mathrm{C}$ for $7 \mathrm{~d}$. DMF was removed from the intermediate product (P[CA-75Pyr 25HEDMA][Cl]) by rotavapor and the remaining solid was re-dissolved in water and purified through dialysis using a SnakeSkin $3.5 \mathrm{kDa}$ MWCO membrane to remove the unreacted starting material. P[CA-75Pyr 25HEDMA][Cl] exchanged anions with $\operatorname{LiTf}_{2} \mathrm{~N}$ ( $3.17 \mathrm{~g}, 0.0110 \mathrm{~mol}, 1.2 \mathrm{eq}$.) to obtain $\mathrm{P}$ [CA-75Pyr-25HEDMA] $\left[\mathrm{Tf}_{2} \mathrm{~N}\right]\left(\mathrm{Pyr}_{3}\right.$ HEDMA $_{1}$, Table 1$)$. The product was washed with water to remove $\mathrm{LiCl}$ and unreacted reagents, and then dried under vacuum at $60^{\circ} \mathrm{C}$ for $24 \mathrm{~h}$. Yield: $5.58 \mathrm{~g} \mathrm{(64 \% )}$

\subsection{6. $\mathrm{Pyr}_{2} \mathrm{HEDMA}_{2}$}

CA-P $(6.0 \mathrm{~g}, 0.00937 \mathrm{~mol})$ solution in DMF $(100 \mathrm{~mL})$ reacted with 2dimethylaminoethanol $(0.86 \mathrm{~mL}, 0.0088 \mathrm{~mol}, 0.9 \mathrm{eq}$.$) and N-methyl-$ pyrrolidine $(0.89 \mathrm{~mL}, 0.0086 \mathrm{~mol}, 0.9 \mathrm{eq}$. $)$ at $80^{\circ} \mathrm{C}$ for $7 \mathrm{~d}$. DMF was removed from the internediate product (P[CA-50 Pyr50 HEDMA][Cl]) 

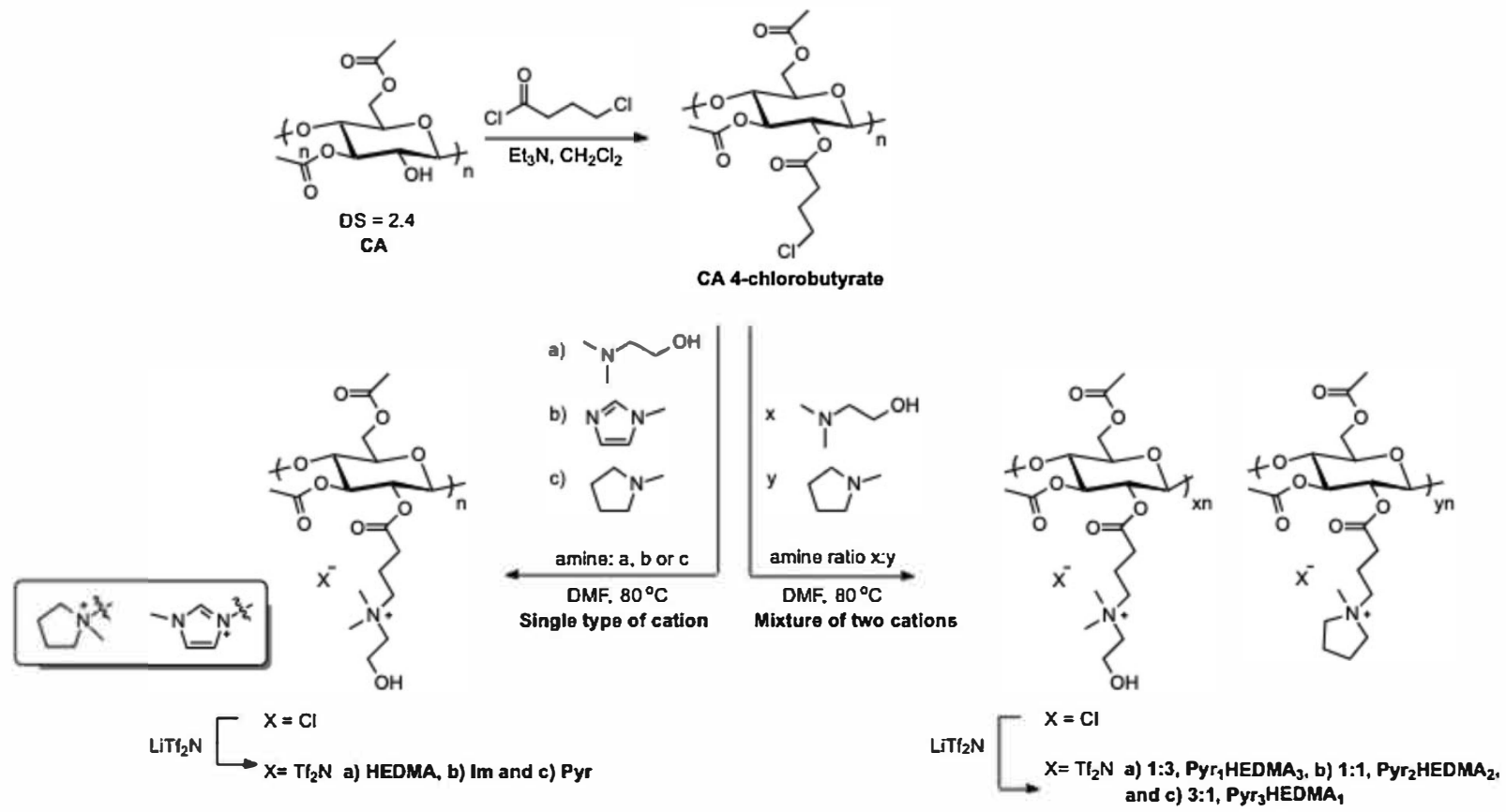

Fig. 1. Post-synthetic conversion of CA into PEs containing single and mixed IL sites via alkylchloride incorporation and subsequent anion metathesis, where HEMA abbreviates hydroxyethyl dimethylamine, Im stands for imidazol, and Pyr for pyrrolidine.

Table 1

CA-based PEs codes based on the ratios of reagents used for incorporation of cationic pendants.

\begin{tabular}{|c|c|c|c|c|}
\hline \multirow[t]{2}{*}{ Material } & \multicolumn{3}{|c|}{ Cationic pendants ${ }^{a}$} & \multirow[t]{2}{*}{ PE code ${ }^{b}$} \\
\hline & {$[\mathrm{Pyr}]^{+}$} & {$[\text {HEDMA }]^{+}$} & {$[\mathrm{Im}]^{+}$} & \\
\hline $\mathrm{CA}$ & - & - & - & $\mathrm{CA}$ \\
\hline $\mathrm{P}[\mathrm{CA}-\mathrm{Im}]\left[\mathrm{Tf}_{2} \mathrm{~N}\right]$ & - & - & 100 & Im \\
\hline $\mathrm{P}[\mathrm{CA}-\mathrm{Pyr}]\left[\mathrm{Tf}_{2} \mathrm{~N}\right]$ & 100 & - & - & Pyr \\
\hline $\mathrm{P}[\mathrm{CA}-\mathrm{HEDMA}]\left[\mathrm{Tf}_{2} \mathrm{~N}\right]$ & - & 100 & - & HEDMA \\
\hline $\mathrm{P}[\mathrm{CA}-75 \mathrm{Pyr}-25 \mathrm{HEDMA}]\left[\mathrm{Tf}_{2} \mathrm{~N}\right]$ & 75 & 25 & - & $\mathrm{Pyr}_{3} \mathrm{HEDMA}_{1}$ \\
\hline $\mathrm{P}[\mathrm{CA}-50 \mathrm{Pyr}-50 \mathrm{HEDMA}]\left[\mathrm{Tf}_{2} \mathrm{~N}\right]$ & 50 & 50 & - & $\mathrm{Pyr}_{2} \mathrm{HEDMA}_{2}$ \\
\hline $\mathrm{P}[\mathrm{CA}-25 \mathrm{Pyr}-75 \mathrm{HEDMA}]\left[\mathrm{Tf}_{2} \mathrm{~N}\right]$ & 25 & 75 & - & $\mathrm{Pyr}_{1} \mathrm{HEDMA}_{3}$ \\
\hline
\end{tabular}

${ }^{a}$ Cationic pendants attempted for grafting on the CA polymer chains in percentage.

b Code of the PEs.

by rotavapor and the remaining solid was re-dissolved in water and purified through dialysis using a SnakeSkin 3.5 kDa MWCO membrane to remove the unreacted starting material. P[CA-50 Pyr50 HEDMA][Cl] exchanged anions with $\operatorname{LiTf}_{2} \mathrm{~N}(2.43 \mathrm{~g}, 0.0084 \mathrm{~mol}, 0.9 \mathrm{eq}$.) to obtain $\mathrm{P}$ [CA-50Pyr-50HEDMA] $\left[\mathrm{Tf}_{2} \mathrm{~N}\right.$ ] $\left(\mathrm{Pyr}_{2} \mathrm{HEDMA}_{2}\right.$, Table 1). The product was washed with water to remove $\mathrm{LiCl}$ and unreacted reagents, and then dried under vacuum at $60^{\circ} \mathrm{C}$ for $24 \mathrm{~h}$. Yield: $2.62 \mathrm{~g} \mathrm{(29 \% )}$

\subsection{7. $\mathrm{Pyr}_{1} \mathrm{HEDMA}_{3}$}

CA-P $(6.0 \mathrm{~g}, 0.00937 \mathrm{~mol})$ solution in DMF $(100 \mathrm{~mL})$ reacted with 2dimethylaninoethanol $(1.29 \mathrm{~mL}, 0.0133 \mathrm{~mol}, 1.4 \mathrm{eq}$.$) and \mathrm{N}$-methylpyrrolidine $(0.44 \mathrm{~mL}, 0.0042 \mathrm{~mol}, 0.4$ eq. $)$ at $80^{\circ} \mathrm{C}$ for $7 \mathrm{~d}$. DMF was removed from the internediate product (P[CA-25 Pyr75HEDMA][Cl]) by rotavapor and the remaining solid was re-dissolved in water and purified through dialysis using a SnakeSkin 3.5 kDa MWCO membrane to remove the unreacted starting material. P[CA-25 Pyr75 HEDMA][Cl] exchanged anions with $\mathrm{LiTf}_{2} \mathrm{~N}$ ( $3.17 \mathrm{~g}, 0.0110 \mathrm{~mol}, 1.2 \mathrm{eq}$.) to obtain $\mathrm{P}$ [CA-25 Pyr-75 HEDMA] [Tf $\left.{ }_{2} \mathrm{~N}\right]\left(\mathrm{Pyr}_{1}\right.$ HEDMA $_{3}$, Table 1$)$. The product was washed with water to remove $\mathrm{LiCl}$ and unreacted reagents, and then dried under vacuum at $60^{\circ} \mathrm{C}$ for $24 \mathrm{~h}$. Yield: $4.2 \mathrm{~g} \mathrm{(28 \% )}$

Table 1 contains all synthesized materials and a reference (CA), including their codes.

\subsection{Membrane preparation}

\subsubsection{Polymeric support}

Polymeric supports were prepared by a phase inversion method (Hermans, Dom, Mariën, Koeckelberghs, \& Vankelecom, 2015; Hołda \& Vankelecon, 2015) from conmercially available polyinide. The casting solution was prepared in a $62.25 / 20.75 / 2.00 \mathrm{wt} \% \mathrm{NMP} / \mathrm{THF} / \mathrm{H}_{2} \mathrm{O}$ solvent mixture with $15 \mathrm{wt} \%$ Matrinid@ 9725 . After homogenisation and degassing, the polymer solution was cast on the non-woven Novatexx $B$ 2483. When the partial evaporation of the solvent was completed (30 s), the support with the polyner layer was transferred into the water bath to induce the liquid-liquid de-mixing and to precipitate the polymer (Vandezande, Gevers, \& Vankelecom, 2008). The supports were cross-linked in $0.63 \mathrm{wt} \% \mathrm{XDA}$ solution in methanol for 3 days to ensure their stability in other solvents Vanherck, Vandezande, Aldea, and Vankelecon (2008).

\subsubsection{Solvent-casting}

The PE-based TFC membranes were prepared using the solution casting method previously reported (Nikolaeva et al., 2017), and consists of casting a dilute polymer solution onto the support inside a metal casting ring, followed by evaporation of the solvent. All PEs were dried under vacuum overnight at $60^{\circ} \mathrm{C}$ to eliminate moisture. Coating solutions were obtained by dissolution of the active polymer in acetone to acquire a final concentration of $4 \mathrm{wt} \%$. The solutions were magnetically stirred to yield a homogeneous phase, filtered, and allowed to degas overnight to avoid the formation of defects.

The supports were fixed inside membrane casting frames to prevent the spillage of PE solution. The solvent-casting was conducted in an airtight container with a controlled flow of nitrogen. A sufficient anount of the casting solution (approx. $0.5 \mathrm{~mL}$ ) was distributed on the surface of the support $(\varnothing 50 \mathrm{~mm})$ to fully fill the gap between the support surface and the top boundary of the casting frame. The solution was left to solidify at $25^{\circ} \mathrm{C}$ under nitrogen atmosphere for at least $24 \mathrm{~h}$.

\subsubsection{Sealing}

A thin sealing layer of PDMS was applied as a final stage of the membrane preparation. A $20 \mathrm{wt} \%$ solution of PDMS in hexane was 
prepared in accordance with the supplier recommendations. The crosslinker was added in 1:10 ratio to the pre-polymer. The solution was then stirred at $60^{\circ} \mathrm{C}$ for $1 \mathrm{~h}$ to allow partial cross-linking of the polymer. The solution was then left to cool for 30 min and was poured on the TFC membrane surface and spread using an automated spin-coater. The membrane was then left to dry in ambient atmosphere.

\subsection{Polyelectrolyte characterisation}

\subsubsection{Nuclear magnetic resonance spectroscopy (NMR)}

The NMR spectra were recorded on a Bruker Avance III $500 \mathrm{MHz}$ $\left({ }^{1} \mathrm{H}\right)$ NMR spectrometer in deuterated acetone (acetone- $\mathrm{d}_{6}$ ). Solvent traces: acetone $(2.05 \mathrm{ppm})$ and water $(2.81 \mathrm{ppm})$.

\subsubsection{Fourier transform infrared spectroscopy (FTIR)}

FTIR spectra of polymers were recorded with a $4 \mathrm{~cm}^{-1}$ resolution and a total number 16 of scans on an ATR-FTIR Jasco 4100 spectrometer $\left(4000-400 \mathrm{~cm}^{-1}\right)$.

\subsubsection{Differential scanning calorimetry (DSC)}

DSC analyses were performed on a DSC instrument from Perkin Elmer (Pyris Diamond DSC) over a temperature range from $0^{\circ} \mathrm{C}$ to $180^{\circ} \mathrm{C}$ under nitrogen flow. The glass transition temperature $\left(T_{g}\right)$ was observed as the inflection point of the heat flow step, recorded in a second run at a scan rate of $20^{\circ} \mathrm{Cmin}^{-1}$. The melting points and the enthalpies for indium $\left(T_{m p}=156.6^{\circ} \mathrm{C}, \Delta H_{m}=28.5 \mathrm{~J} \mathrm{~g}^{-1}\right)$ were used for the calibration of temperature and heat capacity, respectively.

\subsubsection{Thermal gravimetric analysis (TGA)}

Measurements were performed using a Q500 TG-DTA analyzer, manufactured by TA Instruments, in the temperature range between $25^{\circ} \mathrm{C}$ and $700^{\circ} \mathrm{C}$, under nitrogen atmosphere with a heating rate of $10^{\circ} \mathrm{C} \min ^{-1}$.

\subsection{Membrane characterisation}

\subsubsection{Scanning electron microscopy (SEM)}

Scanning electron microscopy. The morphology of TFC membranes was studied using a Hitachi N-3400 SEM applying an acceleration voltage of $15 \mathrm{kV}$. Samples for SEM analysis were prepared from dry membrane segments, quick-frozen in liquid nitrogen to guarantee a sharp break and were sputtered with gold.

\subsubsection{Mixed gas separation}

Mixed-gas permeation tests were performed on a high-throughput gas separation (HTGS) membrane system (HTML, Belgium) implying constant-volume variable-pressure methodology previously described (Khan, Basu, Cano-Odena, \& Vankelecom, 2010). The active membrane area was $1.54 \mathrm{cml}^{2}$. System separation parameters were calculated based on mixed gas selectivity and permeability values. Feed composition was varied to evaluate the influence of $\mathrm{CO}_{2}$ partial pressure on the separation performance. Hence, the $\mathrm{CO}_{2} / \mathrm{N}_{2}$ volume ratio in the feed gaseous mixture increased gradually from $15 / 85$ to $85 / 15$ and entered the membrane cell at $26^{\circ} \mathrm{C}$ and 5 bar pressure. The gas flow rate was set by mass flow controllers (MFC, Bronkhorst). The pressure difference across the membrane was maintained constant with a continuously operating vacuum pump (Pfeiffer Dua 2.5) at 4 mbar on the permeate side.

The feed and permeate gas composition were analysed by gas chromatography (CGC, Interscience). The ratios between mole fractions of gas components downstrean $\left(y_{i}\right.$ and $\left.y_{j}\right)$ and upstream $\left(x_{i}\right.$ and $\left.x_{j}\right)$ comprised the formula for calculating the separation factor of the menbrane, $\alpha_{i / j}^{*}$ :

$\alpha_{i / j}^{*}=\frac{y_{i} / y_{j}}{x_{i} / x_{j}}$ where indexes $(n) i$ and $j$ correspond to single gases $\mathrm{CO}_{2}$ and $\mathrm{N}_{2}$ respectively. Since the upstream pressure considerably exceeds the downstream pressure (vacuum) and no coupling effect between $\mathrm{CO}_{2}$ and $\mathrm{N}_{2}$ was observed, the intrinsic permeability selectivity approaches the separation factor (Petropoulos (1993)):

$\alpha_{i / j}^{*} \approx \alpha_{i / j}$

$\alpha_{i / j}$ is referred to as mixed-gas selectivity further on in the text.

The permeance $\Pi_{n}$ (GPU) was calculated based on the rate of the pressure increase $d p / d t$ obtained when the system has reached the steady state conditions as follows:

$\Pi_{n}=\frac{V_{m}}{R \cdot T \cdot \frac{V \cdot y_{n}}{A \cdot x_{n} \cdot\left(p_{f}-p_{p}\right) \mathrm{dt}}}$

where $A$ is a membrane permeation area $\left(\mathrm{cm}^{2}\right), V$ is a permeation volune downstream of the membrane $\left(\mathrm{cm}^{3}\right), T$ is the operating temperature of the separation unit $(\mathrm{K}), p_{f}$ and $p_{p}$ are the absolute pressure of the gas in the feed and permeate, respectively $(\mathrm{cmHg}), V_{m}$ is the molar volume of gas ( $\left.\mathrm{mol} \mathrm{L}{ }^{-1}\right), R$ is the gas constant $\left(\mathrm{L} \mathrm{cmHg} \mathrm{K}{ }^{-1} \mathrm{~mol}^{-1}\right)$. $p_{p}$ is considered negligible in the vacuum conditions.

\section{Results and discussion}

\subsection{Polyelectrolyte synthesis}

${ }^{1} \mathrm{H}$ NMR confirmed the functionalisation of CA with cationic pendants (Fig. 2). The ${ }^{1} \mathrm{H}$ NMR spectra of amine molecules used as precursors for cationic pendants are reported elsewhere (Coates \& Ridley, 1966; Pluth, Fiedler, Mugridge, Bergman, \& Raymond, 2009; Sigmaaldrich, 2020; Wang, Janout, \& Regen, 2010). CA is identified by the

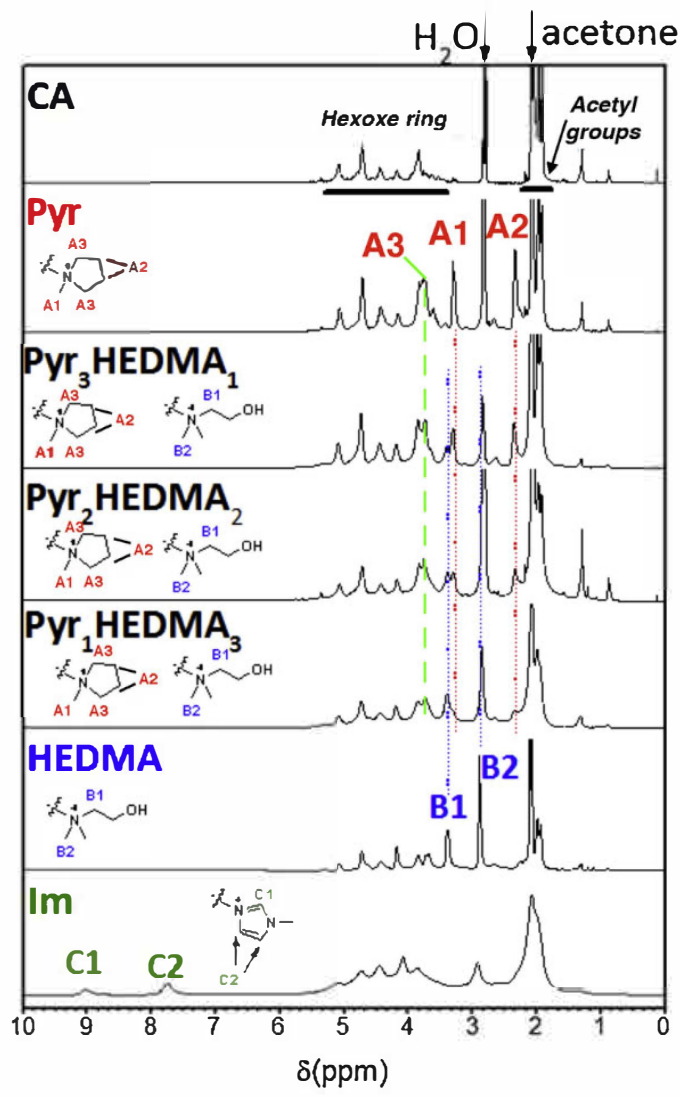

Fig. 2. ${ }^{1} \mathrm{H}$ NMR $\left(500 \mathrm{MHz}\right.$, acetone- $\mathrm{d}_{6}$ ) spectra of CA and CA-derived PEs. Isolated peaks of specific protons, marked with a letter and a number, indicate the corresponding PE structure. 
presence of two main signal sets: those related to protons linked to the hexose ring $(14 \mathrm{H})$ in the range of $5.17-3.25 \mathrm{ppm}$ and those corresponding to acetyl groups $(15 \mathrm{H})$ in the range of $2.08-1.91 \mathrm{ppm}$. While partial overlap of the signals unfortunately hinders the quantitative analysis of the conversion of the acetate groups, also observed in DMSO-d6 (Nikolaeva et al., 2018), the deeper insight into the reaction is obtained from the signal coupling in the COSY spectrum (ESI Fig. 2) and positively confirms the conversion of CA into the desired polyelectrolyte products. These signals reoccur in the spectra of all synthesised PEs. Additionally, the CA-based PEs spectra contain other characteristic signals corresponding to the specific cationic pendants. The signal integration of the peaks assigned to the specific cationic pendants con-firms the cationic pendant incorporation and verifies the functionalisa-tion extent and cationic pendant ratio in the bifunctional PEs.

The Im spectrum (green) presents two characteristic peaks corresponding to the protons of the inidazolium ring at $9.03 \mathrm{ppm}$ and $7.74 \mathrm{ppm}$. The Pyr spectrum (red) has two new isolated peaks at $3.29 \mathrm{ppm}$ (A1) and $2.33 \mathrm{ppm}$ (A2). A1 is assigned to the methyl group (3 protons) of the pyrrolidinium ring, and A2 is assigned to the 3- and 4-positions (- $\mathrm{CH}_{2}-\mathrm{CH}_{2^{-}}$segment (4 protons)) of the same moiety. An addi-tional characteristic signal (A3) arises at $3.78 \mathrm{ppm}$, in the zone of the hexose ring signal, attributed to the remaining protons at 2 - and 5- po-sitions of the pyrrolidinium ring.

HEDMA is functionalised with 2-hydroxyethyldimethylammonium pendant. Its spectrum presents the key signals at $3.37 \mathrm{ppm}$ (B1) assigned to $-\mathrm{N}_{-} \mathrm{CH}_{2}$ - unit $(2 \mathrm{H})$ and at $2.88 \mathrm{ppm}$ (B2) corresponding to the two methyl groups $(6 \mathrm{H})$ at the nitrogen atom. Additionally, the peak at $4.16 \mathrm{ppm}$ is more intense when compared to Pyr. This increase in in-tensity suggests the presence of the protons adjacent to the hydroxyl group. The B1 signal analysis in other samples is hampered by the presence of water traces, which raise a signal at the same chenical shift.

NMR spectra of PEs functionalized with mixed cations present signals of both cationic pendants. In order to determine the relative amount of each cation, one representative signal of each cation was selected: A1, corresponding the methyl group of pyrrolidinium group and B1, corresponding to methylene group of 2-hydroxyethyldimethylammonium group. The integration of the areas under those peaks, followed by division by the number of protons each one represents, allows to determine the relative amount of each group that was actually incorporated to the polymer structure upon the grafting reaction. To do so, in each spectrum, A1 and B1 signals were integrated and divided by corresponding proton number, i.e. the area of $\mathrm{A} 1$ was divided by $3\left(-\mathrm{CH}_{3}\right)$ and the area of $\mathrm{B} 1$ by $2\left(-\mathrm{CH}_{2}-\right)$. From this analysis, the following $\% \mathrm{Pyr} / \%$ HEDMA molar ratios were calculated: 33/69, 44/56 and 58/43 for $\mathbf{P y r}_{1}$ HEDMA $_{3}$, Pyr $_{2}$ HEDMA $_{2}$ and $\operatorname{Pyr}_{3}$ HEDMA $_{1}$, in contrast to the intended 25/75, 50/50 and 75/25. Thus, a higher amount of HEDMA is incor porated, apparently due to a higher reactivity of the dimethylamine nitrogen than the pyrrolidinium nitrogen. Still the synthesised mixed PEs are composed by sufficiently distinct amount of cations that enables the investigation into the effect of pendants content on $\mathrm{CO}_{2}$ separation.

ATR-FTIR spectra confirms the CA functionalisation with cationic pendants containing two main characteristic peak groups (Fig. 3). Firstly, the designated peaks indicate the $\mathrm{C}-\mathrm{O}$ band of the alkyl chain at 1029 and $1219 \mathrm{~cm}^{-1}, \mathrm{C}=\mathrm{O}$ at $1736 \mathrm{~cm}^{-1}$ identify the CA-backbone. In the CA spectrum, a broad $\mathrm{O}-\mathrm{H}$ stretch represents the free hydroxyl groups of the parent material at $3478 \mathrm{~cm}^{-1}$. These free hydroxyls are involved in the esterification reaction with 4-chlorobutyryl chloride for introducing alkyl chloride moieties that participate in the quaternisation reaction with tertiary amines yielding the IL-like cationic pendants on CA. The spectra signals attributed to the tertiary amines used as precursors for cationic pendants may be consulted elsewhere (Carter \& Pemberton, 1997; Hirokawa, Kinuura, Ohno, \& Murata, 1980; Pandey, Awasthi, \& Awasthi, 2013). This signal disappears upon the functionalisation of CA with 1-methylimidazole and 1-methylpyrrolidine cationic pendants. In the case of HEDMA and HEDMA-containing bifunctional PEs, a broad $\mathrm{O}-\mathrm{H}$ stretch at $3550-3200 \mathrm{~cm}^{-1}$ reappears representing the alcohol

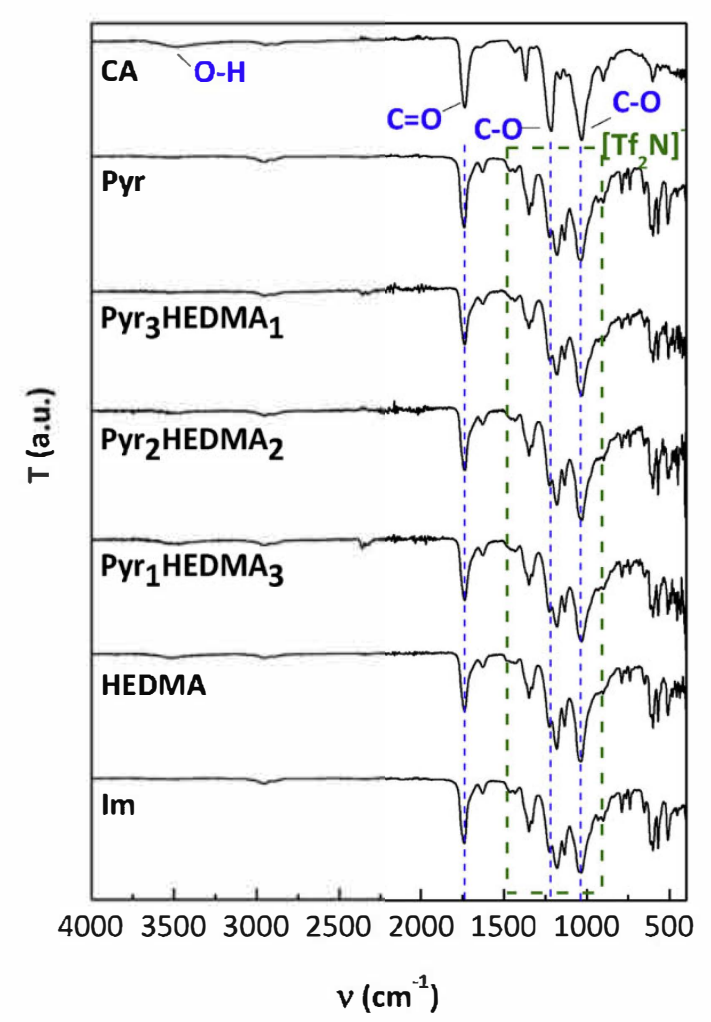

Fig. 3. ATR-FTIR spectra of CA and CA-derived PEs.

groups attached to the quaternary amine cation. This signal intensity increases with the higher amount of 2-hydroxyethyldimethylamine cations being incorporated in the following order: Pyr $_{3}$HEDMA$_{1}<\mathbf{P y r}_{2}$ HEDMA $_{2}<$ Pyr $_{1}$ HEDMA $_{3}<$ HEDMA. Secondly, the bands corresponding to the $\left[\mathrm{Tf}_{2} \mathrm{~N}\right]^{-}$validate the anion exchange reaction at $1344,1323,1173$ and $1128 \mathrm{~cm}^{-1}$.

Fig. 4 depicts the decomposition curves of the monofunctional PEs in comparison to the reference material CA as weight loss (a) and derivative weight (b).

CA degrades in one step with major mass loss of $2.7 \% /{ }^{\circ} \mathrm{C}$ at $375^{\circ} \mathrm{C}$, corresponding to degradation. Residual material that accounts for $10 \%$ of the sample initial mass carbonises at $500^{\circ} \mathrm{C}$. CA shows stronger decomposition stability, by forming intermolecular hydrogen-bonds via -OH groups, which are absent in the synthesised PEs. Furthermore, the PE show lower stability because of the presence of ionic groups or traces of ionic impurities, which may catalyse degradation reactions.

The thernal degradation of PEs shows three steps. In the first step, between $270^{\circ} \mathrm{C}$ and $315^{\circ} \mathrm{C}$, the weight loss is quick for all these PEs, as the side group of the cationic parts reacts. The degradation rates decrease in the order: HEDMA $>$ Pyr $>$ Im at $2.8>2.6>2.3 \% /{ }^{\circ} \mathrm{C}$, respectively. Importantly, the first decomposition stage occurs $5{ }^{\circ} \mathrm{C}$ earlier for the cyclic alkyl ammoniun cation (1-methylpyrrolidine), when compared to the hydroxyl containing aliphatic cation (2-hydroxyethyldimethylamine), and $20^{\circ} \mathrm{C}$ earlier when compared to the aromatic inidazolium cation (1-methylimidazole). This trend suggests the stabilizing effect of the $-\mathrm{OH}$ group and $\pi-\pi$ intermolecular interactions within the investigated PEs.

In the second step, between $320^{\circ} \mathrm{C}$ and $400^{\circ} \mathrm{C}$, PEs degrade through pyrolysis and form initial char products. This range also overlaps with the degradation process in the parent material CA. In the third step, above $400^{\circ} \mathrm{C}$, the formation of char is completed. The curves flatten above $500{ }^{\circ} \mathrm{C}$ indicating final decomposition of the PEs, with approximately $20 \%$ residue of the initial weight.

Fig. 4 (b) inset depicts the decomposition curves of bifunctional PEs. Sinilar to the monofunctional PEs, a three steps mechanism describes 


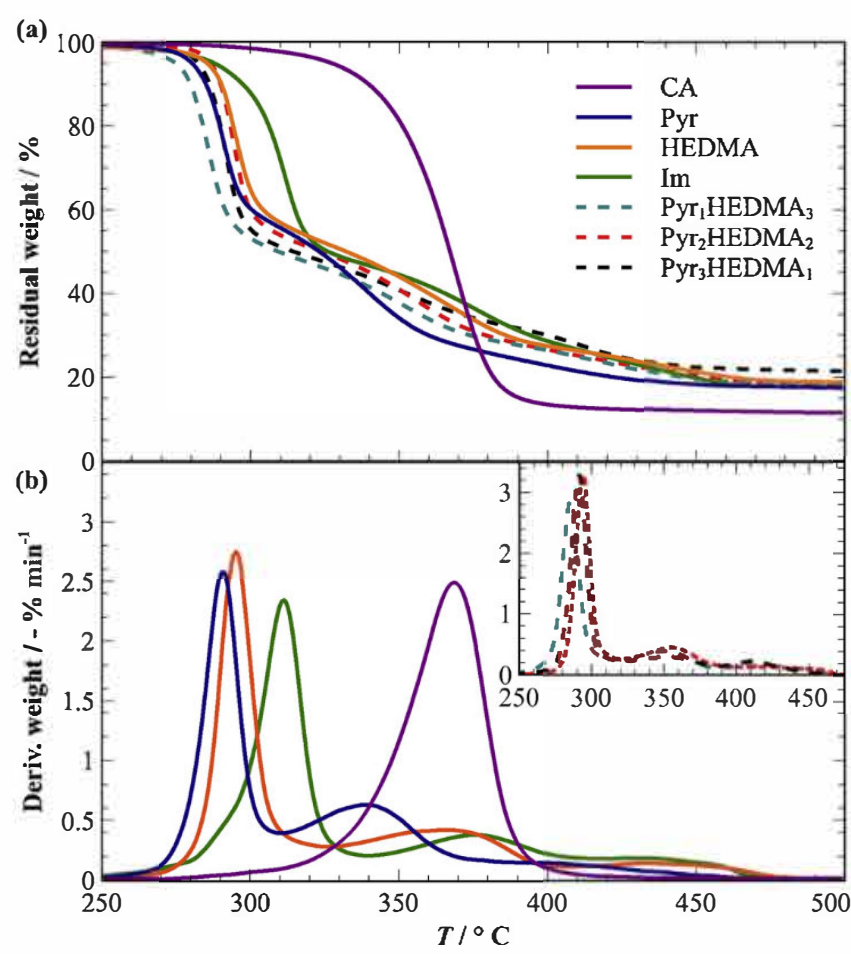

Fig. 4. TGA curves of $C A$ and CA-derived PEs, plotting the residual weight (a) and derivative weight (b) as a function of the temperature. The inset shows the derivative weight losses for the Pyr/HEDMA copolymers.

the degradation process. Only relatively small changes in the position of peaks and degradation rates are observed, since the material composition varies only in the ratios of 1-methylpyrrolidine and 2-hydroxyethyldimethylamine cationic pendants. The char residue left after complete degradation of mixed PEs equals ca. $20 \%$ of the initial weight and corresponds to the weight left after the monofunctional PEs decomposition.

Incorporation of cationic pendants reduces the glass transition of CAbased PEs when compared to the parent CA. Table 2 contains the glass transition temperatures $\left(T_{g}\right)$ of all the materials investigated. The pristine CA $T_{g}$ of $190^{\circ} \mathrm{C}$ corresponds well with the literature (Deng et al., 2016). When compared to the parent material, the CA-based PEs show ca. $60^{\circ} \mathrm{C}$ lower $T_{g}$ decreasing in the following order: 131,128 and $126^{\circ} \mathrm{C}$, for Im, HEDMA, Pyr, respectively. This general decrease in $T_{g}$ for mono- and bifunctional PEs indicates the disruption of intermolecular hydrogen bonds between the $\mathrm{O}-\mathrm{H}$ and $\mathrm{C}=\mathrm{O}$ moieties upon the

\section{Table 2}

Summaly of physico-chemical properties of PEs $\left(T_{g}\right)$ and TFC membranes with selective PE-based layer.

\begin{tabular}{lllll}
\hline PE code & $\mathrm{T}_{\mathrm{g}}{ }^{\mathrm{a}}$ & \multicolumn{3}{l}{ Membrane thickness } \\
\cline { 4 - 5 } & {$\left[{ }^{\mathrm{b}} \mathrm{C}\right]$} & $\bar{\delta}_{\mathrm{TOT}}{ }^{\mathrm{C}}[\mu \mathrm{m}]$ & $\bar{\delta}_{\text {PIL }}{ }^{\mathrm{d}}[\mu \mathrm{m}]$ & $\bar{\delta}_{\text {PDMS }}{ }^{\mathrm{e}}[\mu \mathrm{m}]$ \\
\hline $\mathrm{CA}$ & 191 & - & $12.8 \pm 9.1$ & 4 \\
$\mathrm{Im}$ & 131 & 54 & $9.0 \pm 0.7$ & 5 \\
Pyr & 126 & 103 & $6.7 \pm 2.6$ & 4 \\
HEDMA & 128 & 44 & $9.9 \pm 0.4$ & 6 \\
Pyr $_{3}$ HEDMA $_{1}$ & 136 & 114 & $15.0 \pm 12.6$ & 6 \\
$\mathbf{P y r}_{2}$ HEDMA $_{2}$ & 134 & 97 & $17.2 \pm 8.2$ & 6 \\
Pyr $_{1}$ HEDMA $_{3}$ & 133 & 129 & $28.5 \pm 2.1$ & 5 \\
\hline
\end{tabular}

a Glass transition temperature.

b Membrane thickness estimated using the SEM software, as an average over three samples.

${ }^{c}$ Average total thickness of the TFC membrane excluding the non-woven, estiniated from SEM.

d Average thickness of the selective PIL layer estinated from SEM.

e Average thickness of the sealing PDMS layer estimated from SEM. functionalisation. Additionally, the incorporation of asymmetric cationic pendants may disrupt the polymer chain packing and further decrease the $T_{g}$ values.

The bifunctional PEs display slightly higher $T_{g}$ values than the monofunctional PEs containing 1-methylpyrrolidine and 2-hydroxyethyldimethylamine cationic pendants, decreasing in the following order: 136,134 and $133^{\circ} \mathrm{C}$, for $\mathbf{P y r}_{3} \mathrm{HEDMA}_{1}, \mathrm{Pyr}_{2} \mathrm{HEDMA}_{2}, \mathrm{Pyr}_{1}$ HEDMA $_{3}$, respectively. The difference in within the experimental error of the DSC measurements and is therefore too small to attribute any specific properties to the individual cationic groups.

\subsection{Membrane preparation}

SEM images in Fig. 5 demonstrate a typical TFC membrane morphology. The morphology of the reference CA membrane is shown in Fig. 5a (Nikolaeva et al., 2018). The approxinuate thickness of the individual layers was estinated from SEM inages (Table 2) and ranges from $6.7 \mu \mathrm{m}$ for PYR to $28.5 \mu \mathrm{m}$ for $\mathrm{Pyr}_{1} \mathrm{HEDMA}_{3}$. Casual differences in the thickness may be caused by uneven distribution of the solution on the surface, slight variations of the support thickness that cause the solution to flow to the lower/thinner areas, meniscus formation at the casting ring, etc. These values may be used for the assessment of the permeability coefficients based on the acquired permeances. Although this approach allows the good estimation of the order of magnitude of the perneability, the thickness measurements by SEM may not be fully representative as they remain extremely local.

The PE layer boundary exhibits a smooth transition into the support beneath. This observation suggests good adhesion between the CA-based PEs and the support without the penetration of the selective layer in the PI support. They had a visibly snooth and shiny appearance, confirming the formation of a homogeneous dense film, as reported previously (Nikolaeva et al., 2018), and aligning well with recent research on CA propionate films functionalised with ionic liquids (Kujawa et al., 2019). The average thickness of the selective PE layer among all membrane samples equals $14.2 \pm 5.1 \mu \mathrm{m}$.

\section{3. $\mathrm{CO}_{2} / \mathrm{N}_{2}$ separation performance}

\subsubsection{Influence of the cationic pendant}

Fig. 6a presents the measured $\mathrm{CO}_{2}$ permeance and Fig. $6 \mathrm{~b}$ presents the $\mathrm{CO}_{2} / \mathrm{N}_{2}$ mixed-gas selectivity in $\mathrm{CA}$ and monofunctional PE-based membranes (Im, Pyr, and HEDMA) as a function of $\mathrm{CO}_{2}$ partial pressure.

$\mathrm{CO}_{2}$ perneated through the $\mathbf{C A}$-coated membrane at approx. $70 \mathrm{GPU}$ with a moderate decline in $\mathrm{CO}_{2}$ permeance with increasing $\mathrm{CO}_{2}$ partial pressure (Ahmad, Jawad, Low, \& Zein, 2014; Lu et al., 2016). Im and HEDMA showed slightly descending trends in $\Pi_{\mathrm{CO}_{2}}$, while Pyr showed an increase and stabilisation of $\Pi_{\mathrm{CO}_{2}}$ at higher $\mathrm{CO}_{2}$ concentrations in the feed. The sample with Pyr was close to the performance of previously reported Pyr-based membrane (Nikolaeva et al., 2018).

The $\mathrm{N}_{2}$ permeance followed similar trends as the respective $\Pi_{\mathrm{CO}_{2}}$ of the CA-based PEs and CA (Fig. 6b). Over the entire composition range, the cationic pendants improve the performance of the membranes with respect to the neat CA membrane, maintaining a slightly higher $\mathrm{CO}_{2} / \mathrm{N}_{2}$ selectivity. Remarkably, in the case of Pyr groups, $\Pi_{\mathrm{N}_{2}}$ and $\Pi_{\mathrm{CO}_{2}}$ both increase with increasing $\mathrm{CO}_{2}$ partial pressure with almost constant selectivity. Since the permeability is strongly correlated to the material's stiffness (Friess et al., 2012; Fucco et al., 2019), even small amounts of adsorbed $\mathrm{CO}_{2}$ probably reduced the inter- and intra-chain interactions between the pyrrolidinium-containing units, thus increasing the chain mobility and the permeability for both gases.

The two behaviours observed in Fig. 6a and b, i.e. moderate decay in $\Pi_{\mathrm{CO}_{2}}$ for Im and HEDMA and moderate increase in $\Pi_{\mathrm{CO}_{2}}$ for Pyr as a function of $p_{\mathrm{CO}_{2}}$, suggest that two mechanisms govern the overall $\mathrm{CO}_{2}$ transport through the PE-based membranes. In the case of Pyr, the increase of $\Pi_{\mathrm{CO}_{2}}$ to a constant value with increasing $\mathrm{CO}_{2}$ partial pressure indicates higher chain mobility in the presence of absorbed $\mathrm{CO}_{2}$, as 


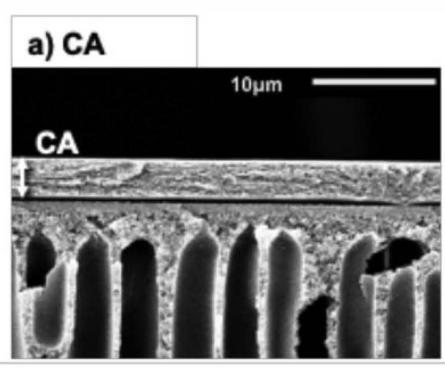

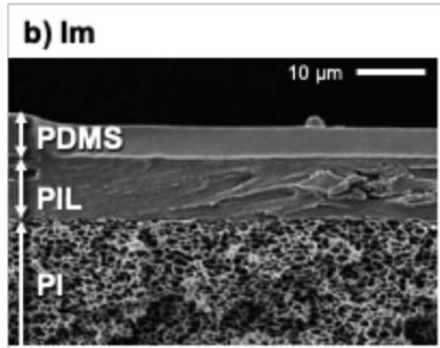

c) Pyr

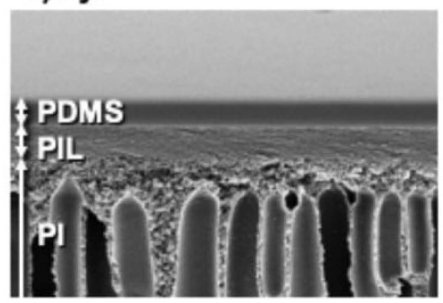

f) $\mathrm{Pyr}_{2} \mathrm{HEDMA}_{2}$

e) Pyr $_{3}$ HEDMA $_{1}$
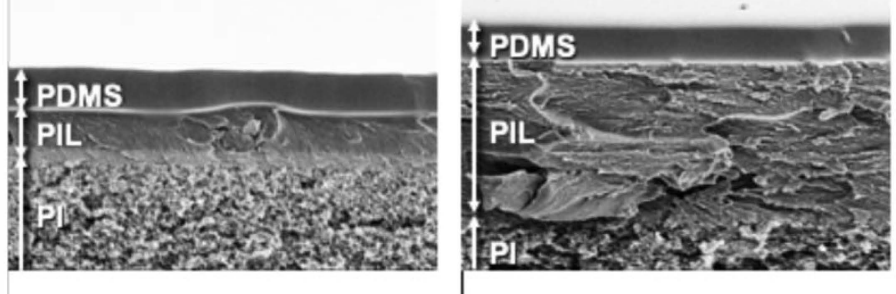

\section{d) HEDMA}

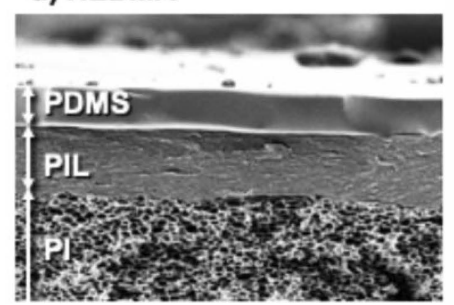

g) $\mathrm{Pyr}_{1} \mathrm{HEDMA}_{3}$

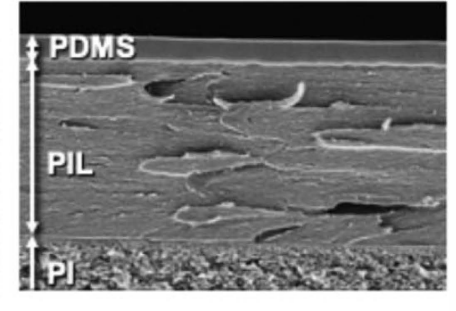

Fig. 5. Cross-sectional SEM capture the morphology of thin-film composite membranes: (a) CA adapted from (Nikolaeva et al., 2018), (b) Im, (c) Pyr, (d) HEDMA, (e) $\mathrm{Pyr}_{3} \mathrm{HEDMA}_{1}$, (f) $\mathrm{Pyr}_{2} \mathrm{HEDMA}_{2}$, and (g) $\mathrm{Pyr}_{1} \mathrm{HEDMA}_{3}$. Alrows indicate the thickness of the respective layer: PI support, selective layer, and PDMS sealing. The scale bar indicated in (a) for CA, and (b) for PE-based TFC membranes and is identical for all images (c-g).

discussed above. Since $\mathrm{CO}_{2}$-induced plasticisation generally takes place at $\mathrm{CO}_{2}$ partial pressures above approxinately 10 bar (Schuldt, Pohlmann, Shishatskiy, \& Brinkmann, 2018), which is higher than those used in the present work. Thereofre, the increasing $\mathrm{II}_{\mathrm{CO}_{2}}$ in Pyr is likely due to the interactions of $\mathrm{CO}_{2}$ with the pyrrolidine groups, creating additional free volume, whereas in the other polymers the transport process is doninated by the decrease of $\mathrm{CO}_{2}$ solubility due to strong dual mode sorption. This causes a decrease in $\mathrm{CO}_{2}$ permeance with pressure, as generally observed in glassy polymers. The looser packing of Pyr is probably due to the bulky pyrrolidine groups that allow weaker interand intra-chain interactions. In the case of Im and HEDMA, the decrease in $\Pi_{\mathrm{CO}_{2}}$ with increasing $\mathrm{CO}_{2}$ partial pressure suggests either carrier saturation behaviour, ascribed to facilitated transport (Ho \& Dalrymple, 1994; Quinn, Appleby, \& Pez, 1995; Zou \& Ho, 2006), or the saturation of conventional Langnutir sorption sites. The first interpretation is consistent with our hypothesis that inidazol and hydroxyl based cationic pendants would intensify interactions with $\mathrm{CO}_{2}$ more significantly than pyrolidinium-based cationic pendants, as also suggested in related research (Green, Grubjesic, Lee, \& Firestone, 2009; Simon et al., 2018). The second hypothesis follows a more conventional transport behaviour with dual-mode sorption, where lower $\mathrm{CO}_{2}$ permeability may either be ascribed to saturation of the Langniur sorption sites, and thus to a lower solubility, or to strong affinity of the electrolyte group for $\mathrm{CO}_{2}$, leading to reduced diffusivity. The latter was also observed by Tomé et al. for a structurally sinilar choliniun-based polyelectrolyte (Tomé, Gouveia, Freire, Mecerreyes, \& Marrucho, 2015) and has been demonstrated for other polymers such as polymers of intrinsic microporosity as well, where anine-functionality in the polyner leads to a deviation of the $\mathrm{CO}_{2}$ diffusion coefficient from the usual trend as a function of the gas size (Fuloco et al., 2019).

The $\mathrm{CO}_{2} / \mathrm{N}_{2}$ selectivity slightly decreased with increasing $\mathrm{CO}_{2}$ partial pressure for CA (Lu et al., 2016; Nikolaeva et al., 2018). For all PEs, the $\mathrm{CO}_{2} / \mathrm{N}_{2}$ selectivity initially inproved or remained constant with increasing $\mathrm{CO}_{2}$ partial pressure up to $50 \mathrm{vol} \% \mathrm{CO}_{2}$ in the feed mixture. Even further increase in $\mathrm{CO}_{2}$ concentration led to a moderate decline in $\boldsymbol{\alpha}_{\mathrm{CO}_{2} / \mathrm{N}_{2}}$, with PEs approximating the performance of pure CA. Importantly, the pure PE-coated menbranes show their potential to maintain the $\alpha_{\mathrm{CO}_{2} / \mathrm{N}_{2}}$ with increasing $\mathrm{CO}_{2}$ partial pressure, while CA follows the dual mode sorption behaviour. These findings emphasise that incorporation of cationic pendants into CA-backbone may be beneficial for the $\mathrm{CO}_{2} / \mathrm{N}_{2}$ separation perfornance, and might enable the formation of more efficient PE-based membranes.

\subsubsection{Polyelectrolytes with bifunctional cationic pendants}

Fig. 7a and b represent the measured $\mathrm{CO}_{2}$ and $\mathrm{N}_{2}$ permeance, respectively, and Fig. $7 \mathrm{c}$ the $\mathrm{CO}_{2} / \mathrm{N}_{2}$ mixed-gas selectivity, in bifunctional PEs $\left(\mathrm{Pyr}_{3} \mathrm{HEDMA}_{1}, \mathrm{Pyr}_{2} \mathrm{HEDMA}_{2}\right.$, and $\left.\mathrm{Pyr}_{1} \mathrm{HEDMA}_{3}\right)$ based membranes compared to monofunctional PE (Pyr and HEDMA)-based membranes.

$\Pi_{\mathrm{CO}_{2}}$ of 1-methylpyrrolidine rapidly decays with increasing HEDMA content in the CA-based mixed PEs being almost independent of the $\mathrm{CO}_{2}$ partial pressure in the feed nixture (Fig. 7a). However, $\Pi_{\mathrm{CO}_{2}}$ recovers slightly in the monofunctional HEDMA-based membrane. This suggests that the decrease in $\Pi_{\mathrm{CO}_{2}}$ is affected by the packing of the PE chains, which depends on the steric interference between the pendants. In addition, $\Pi_{\mathrm{CO}_{2}}$ decreases slightly for all PEs with increasing $\mathrm{CO}_{2}$ partial pressure in the feed nixture. This effect is most pronounced in PEs with higher amounts of hydroxyethyl-containing cationic pendant: $\mathbf{P y r}_{1}$. HEDMA $_{3}$ and HEDMA. This supports the assumption that hydroxyl containing cationic pendant fosters interaction with $\mathrm{CO}_{2}$ molecules by increasing the affinity of PEs towards $\mathrm{CO}_{2}$. Thus, lower $\Pi_{\mathrm{CO}_{2}}$ signifies saturation of the carrier sites and deceleration of mass transfer in the 

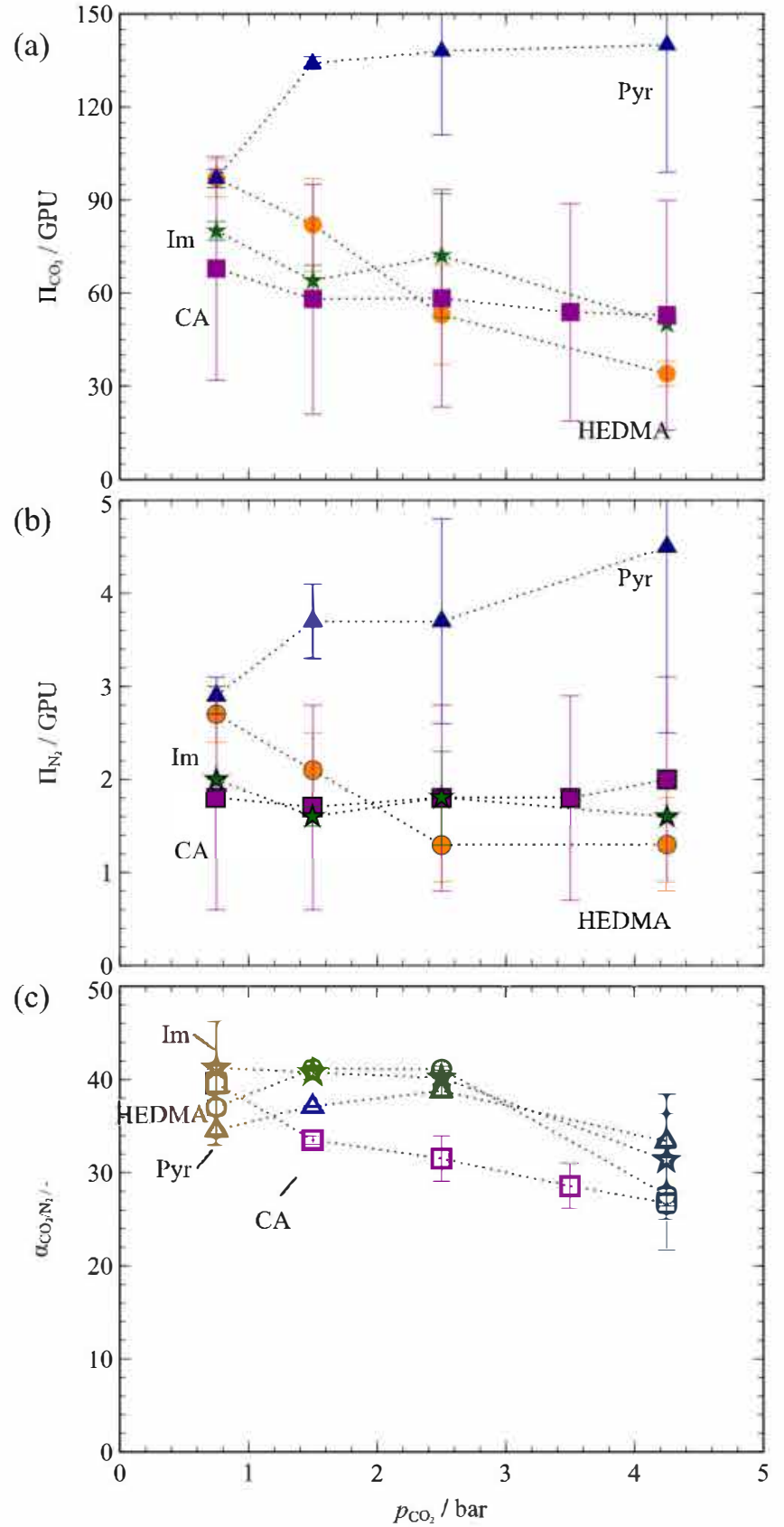

Fig. 6. Influence of $\mathrm{CO}_{2}$ partial pressure increase at $26^{\circ} \mathrm{C}$ by varying composition from 15 to $85 \mathrm{vol} \% \mathrm{CO}_{2}$ at constant pressure of 5 bar on separation parameters of PEs with single cationic sites: (a) and (b) $\mathrm{CO}_{2}$ and $\mathrm{N}_{2}$ permeance (closed markers), respectively, and (c) $\mathrm{CO}_{2} / \mathrm{N}_{2}$ mixed gas selectivity (open markers).

active layer. In conclusion, the rate of $\Pi_{\mathrm{CO}_{2}}$ decay depends on the ratio of Pyr and HEDMA grafted on the CA-backbone with pure Pyr having the highest and the most stable $\Pi_{\mathrm{CO}_{2}}$.

Similarly to $\mathrm{CO}_{2}$ permeance, $\Pi_{\mathrm{N}_{2}}$ gradually diminished with increasing HEDMA content in the CA-backbone. Here the increase in $\mathrm{CO}_{2}$ partial pressure in the feed affects $\Pi_{\mathrm{N}_{2}}$ to a lesser extent than it does affect $\Pi_{\mathrm{CO}_{2}}$. As $\mathrm{N}_{2}$ is less soluble than $\mathrm{CO}_{2}$, its mass transfer mechanism is dominated by the diffusion that is less pressure dependent (Nikolaeva et al., 2018).

In Fig. 7 pure PEs, Pyr and HEDMA, reach the highest $\alpha_{\mathrm{CO}_{2} / \mathrm{N}_{2}}$, with a local minimum in the mixed PEs with higher content of 1-methylpyrrolidine cationic pendant. While, the PE with $25 \%$ of 1 -methylpyrrolidine content positions itself close to the pure HEDMA. Thus, hydroxyethyl-
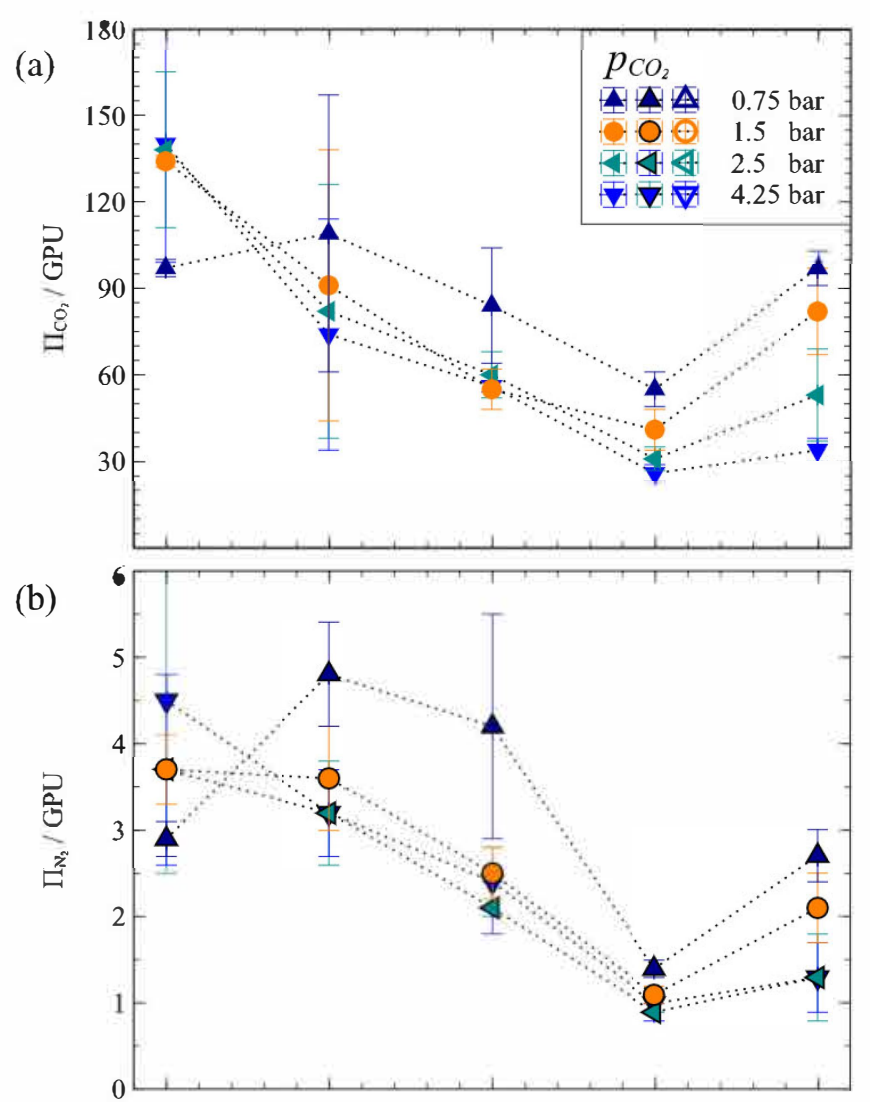

(c)

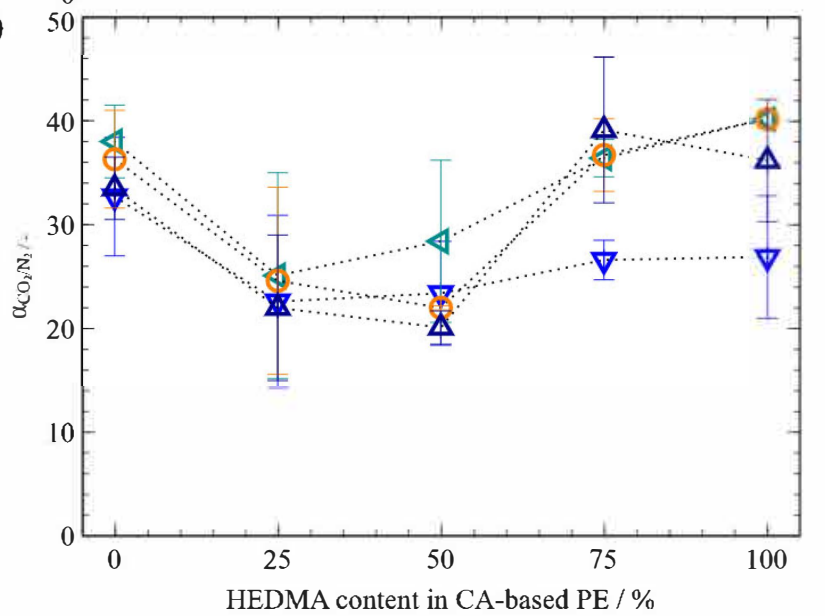

Fig. 7. Influence of HEDMA content on separation performance of PEs with bifunctional pendants: (a) and (b) $\mathrm{CO}_{2}$ and $\mathrm{N}_{2}$ permeance (closed markers), respectively, and (c) $\mathrm{CO}_{2} / \mathrm{N}_{2}$ mixed gas selectivity (open markers) at increasing partial pressures of $\mathrm{CO}_{2}$ at $26^{\circ} \mathrm{C}$ by varying composition from 15 to 85 vol.\% $\mathrm{CO}_{2}$ at constant pressure of 5 bar.

containing cationic pendants positively affect the $\alpha_{\mathrm{CO}_{2} / \mathrm{N}_{2}}$. In addition, the PEs with high 1-methylpyrrolidine content (100\% to 50\%) maintains a stable $\alpha_{\mathrm{CO}_{2} / \mathrm{N}_{2}}$ over the whole range of $\mathrm{CO}_{2}$ partial pressures. Interestingly, $\mathrm{Pyr}_{1} \mathrm{HEDMA}_{3}$ and HEDMA lose $30 \%$ of their $\alpha_{\mathrm{CO}_{2} / \mathrm{N}_{2}}$ at $4.5 \mathrm{bar}$ $\mathrm{CO}_{2}$ partial pressure.

3.3.3. CA-derivatives among other PEs for $\mathrm{CO}_{2}$ separation from flue gas

The Robeson-Merkel plot in Fig. 8 summarises the separation performance of investigated pure and mixed PEs among the literature data on $\mathrm{CO}_{2} / \mathrm{N}_{2}$ separation (Nikolaeva \& Luis, 2020). Overall, the synthesised PEs are positioned among similar PE-based TFC membranes and close to the industrial CA standard, which underscores the dominant role of the 


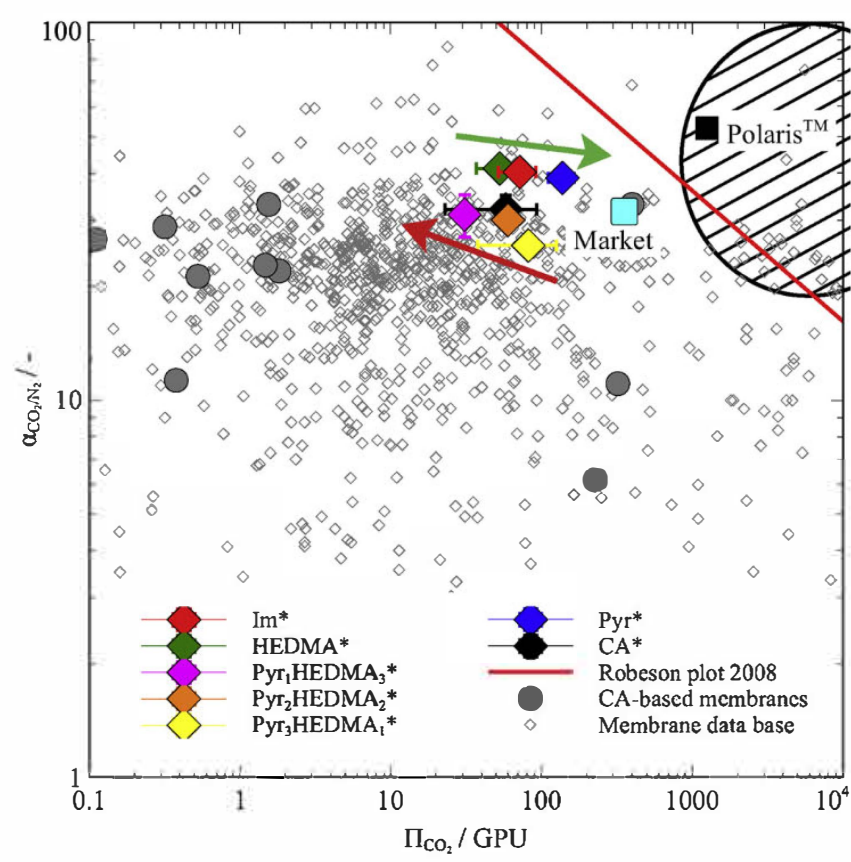

Fig. 8. Position of CA-based PEs membranes on the Robeson-Merkel plot for $\mathrm{CO}_{2}$ separation from flue gas. The green arrow indicates the direction of $\Pi_{\mathrm{CO}_{2}}$ increase in pure PEs, while the red arrow indicates the trade-off behaviour between $\alpha_{\mathrm{CO}_{2} / \mathrm{N}_{2}}$ and $\Pi_{\mathrm{CO}_{2}}$ affected by the prevalence of either 2-hydroxyethyldi-methylamine or 1-methylpyrrolidine cationic pendants in the CA-based PEs. The cyan square represents the market standard for $\mathrm{CO}_{2}$ removal from natural gas (CA-based) and the value indicated with the black square represents the best performing membrane for $\mathrm{CO}_{2}$ capture available on the market. CA-based membranes depict the data obtained from selected publications (ESI Table 1) based on the Australasian Membrane Society Database (Thornton, Freeman, \& Robeson, 2020). The striped area suggests the desirable separation performance of $\mathrm{CO}_{2}$ selective membranes for efficient capture from flue gas (Merkel et al., 2010). (For interpretation of the references to colour in this figure legend, the reader is referred to the web version of this article.)

polymeric backbone in the material matrix (Thornton et al., 2020). Thus, the preserved CA backbone will support the flexibility in the process of membrane preparation that is attributed to CA membranes for gas separation. Nevertheless, the enhanced $\alpha_{\mathrm{CO}_{2} / \mathrm{N}_{2}}$ for pure PEs confirms the positive effect of cationic pendants on the separation of $\mathrm{CO}_{2}$ molecules. $\Pi_{\mathrm{CO}_{2}}$ increases in the following order: HEDMA $<$ Im $<$ Pyr, which is in agreement with the available literature (Nikolaeva et al., 2017; Shaplov, Ponkratov, \& Vygodskii, 2016; Tomé et al., 2015). The trade-off behaviour between $\Pi_{\mathrm{CO}_{2}}$ and $\alpha_{\mathrm{CO}_{2} / \mathrm{N}_{2}}$ in mixed PEs suggests an inportant interplay between the steric parameters of cationic pendants, which affect the final PE perfornance. Moreover, the charge density distribution in the ion pair will considerably influence the intermolecular interactions between polyner chains (Ficke \& Brennecke, 2010; Pinkert, Marsh, Pang, \& Staiger, 2009). The presence of a hydroxyl group in 2-hydroxyethyl-dimethylanine cationic pendant further facilitates the reinstalment of hydrogen bonding between the polymer chains.

Finally, $\mathrm{CO}_{2}$ selectivities of synthesised CA-based PEs correlate well with recent performance reports on the broader range of $\mathrm{PE}$ materials designed for $\mathrm{CO}_{2}$ capture membranes (Lilleby Helberg, Dai, Ansaloni, \& Deng, 2020; Morozova et al., 2017; Nellepalli, Tomé, Vijayakrishna, \& Marrucho, 2019; Nikolaeva \& Luis, 2020; Teodoro et al., 2018; Tomé, Guerreiro, Teodoro, Alves, \& Marrucho, 2018; Zulfiqar et al., 2019).

\section{Conclusions}

Cellulose acetate was modified with cationic pendants to direct the development of polyelectrolytes towards sustainable and robust use in
$\mathrm{CO}_{2}$ separations. The type of cationic pendant grafted on the $\mathrm{CA}$ backbone significantly influences the overall PE separation performance. Importantly, cationic pendants with higher affinity to $\mathrm{CO}_{2}(1-$ methylimidazol) or ability to form hydrogen bonds (2-hydroxyethyldimethylamine) improve $\alpha_{\mathrm{CO}_{2} / \mathrm{N}_{2}}$. Additionally, the cationic pendant type affects the transport mechanism across the membrane. For the PEs with two types of cationic pendants present, the HEDMA cationic pendant plays a dominant role in the separation perfornance of the composite membranes, leading to efficiency loss with increasing partial pressure of $\mathrm{CO}_{2}$. This behaviour can be circunvented by adding 2hydroxyethyl-dimethylamine-based IL with lowere viscosity as a plasticiser to Pyr matrix and further inproving the $\Pi_{\mathrm{CO}_{2}}$. This work attempts to highlight the potential of top-down PEs prepared from conventional polymers with intent to foster their industrialisation in membrane-based $\mathrm{CO}_{2}$ capture.

\section{CRediT author statement}

Daria Nikolaeva: Conceptualization, Methodology, Validation, Formal Analysis, Data Curation, Writing - Original Draft, Writing Review \& Editing, Visualization, Supervision, Project Administration.

Katrien Verachtert: Investigation, Formal Analysis.

Itxaso Azcune: Conceptualization, Methodology, Validation, Formal Analysis, Writing - Review \& Editing, Visualization, Supervision, Resources.

Johannes C. Jansen: Writing - Review \& Editing, Visualization, Supervision

Ivo F.J. Vankelecom: Resources, Writing - Review \& Editing, Supervision, Funding acquisition.

\section{Acknowledgements}

The financial support of this project by the European Union Seventh Framework Progranme FP7/2007-2013 under grant agreement $n^{\circ}$ 608535 is gratefully acknowledged. The authors are also grateful for the financial support from KU Leuven (C16/17/005) and an Erasmus Mundus fellowship funded by EACEA (EUDIME doctoral programme 4th edition).

\section{Appendix A. Supplementary data}

Supplementary data associated with this article can be found, in the online version, at https://doi.org/10.1016/j.carbpol.2020.117375.

\section{References}

Ahmad, A., Jawad, Z., Low, S., \& Zein, S. (2014). A cellulose acetate/multi-walled carbon nanotube mixed matrix membrane for $\mathrm{CO}_{2} / \mathrm{N}_{2}$ separation. Journal of Membrane Science, 451, 55-66. https://doi.org/10.1016/j.memsci.2013.09.043

Ahmadiannamini, P., Li, X., Goyens, W., Joseph, N., Meesschaert, B., \& Vankelecom, I. F. (2012). Multilayered polyelectrolyte complex based solvent resistant nanofiltration membranes prepared from weak polyacids. Journal of Membrane Science, 394-395, 98-106. https://doi.org/10.1016/j.memsci.2011.12.032

Baker, R. W., \& Lokhandwala, K. (2008). Natural gas processing with membranes: An overview. Industrial \& Engineering Chemistry Research, 47, 2109-2121. https://doi. org/10.1021/ie071083w

Bakonyi, P., Nemestóthy, N., \& Bélafi-Bakó, K. (2013). Biohydrogen purification by membranes: An overview on the operational conditions affecting the performance of non-porous, polymeric and ionic liquid based gas separation membranes. International Journal of Hydrogen Energy, 38, 9673-9687. https://doi.org/10.1016/j. ijhydene.2013.05.158. http://www.sciencedirect.com/science/article/pii/ S0360319913013906

Basu, S., Khan, A. L., Cano-Odena, A., Liu, C., \& Vankelecom, I. F. J. (2010). Membranebased technologies for biogas separations. Chemical Society Reviews, 39, 750-768. https://doi.org/10.1039/B817050A

Carter, D. A., \& Pemberton, J. E. (1997). Raman spectroscopy and vibrational assignments of 1- and 2-methylimidazole. Journal of Raman Spectroscopy, 28, 939-946. https://doi.org/10.1002/(SICI)1097-4555(199712)28:12<939::AID JRS186>3.0.CO;2-R

Chen, J., Zhang, J., Feng, Y., Wu, J., He, J., \& Zhang, J. (2014). Synthesis, characterization, and gas permeabilities of cellulose derivatives containing adamantane groups. Journal of Membrane Science, 469, 507-514. https://doi.org/ 
10.1016/j.memsci.2014.06.010. http://inkinghub.elsevier.com/retrieve/pii /S0376738814004566

Coates, B. G. E., \& Ridley, D. (1966). Reactions between some organozinc compounds and 2-Dimethyl-aminoethanol, Acetoxime, Phenylisocyanate, and Benzophenone. Some observations on the Methylzinc Methoxide Tetramer. Journal of the Chemical Society (A).

Deng, J., Bai, L., Zeng, S., Zhang, X., Nie, Y., Deng, L., et al. (2016). Ether-functionalized ionic liquid based composite membranes for carbon dioxide separation. RSC Advances, 6, 45184-45192. https://doi.org/10.1039/C6RA04285F

Ding, Y. (2020). Perspective on Gas Separation Membrane Materials from Process Economics Point of View. Industrial and Engineering Chemistry Research, 59, 556-568. https://doi.org/10.1021/acs.iecr.9b05975

Esposito, E., Dellamuzia, L., Moretti, U., Fuoco, A., Giorno, L., \& Jansen, J. C. (2019). Simultaneous production of biomethane and food grade $\mathrm{CO}_{2}$ from biogas: An industrial case study. Energy \& Environmental Science, 12, 281-289. https://doi.org/ 10.1039/C8EE02897D

Ficke, L. E., \& Brennecke, J. F. (2010). Interactions of ionic liquids and water. Journal of Physical Chemistry B, 114, 10496-10501. https://doi.org/10.1021/jp1012736

Frade, R. F., \& Afonso, C. A. (2010). Impact of ionic liquids in environment and humans: An overview. Human and Experimental Toxicology, 29, 1038-1054. https://doi.org/ $10.1177 / 0960327110371259$

Friess, K., Jansen, J. C., Bazzarelli, F., Izák, P., Jarmarová, V., Kačírková, M., et al. (2012). High ionic liquid content polymeric gel membranes: Correlation of membrane structure with gas and vapour transport properties. Journal of Membrane Science, 415-416, 801-809. https://doi.org/10.1016/j.memsci.2012.05.072

Fuoco, A., Rizzuto, C., Tocci, E., Monteleone, M., Esposito, E., Budd, P. M., et al. (2019). The origin of size-selective gas transport through polymers of intrinsic microporosity. Journal of Materials Chemistry A, 7, 20121-20126. https://doi.org/ 10.1039/C9TA07159H

Galizia, M., Chi, W. S., Smith, Z. P., Merkel, T. C., Baker, R. W., \& Freeman, B. D. (2017). 50th Anniversary Perspective: Polymers and Mixed Matrix Membranes for Gas and Vapor Separation: A Review and Prospective Opportunities. Macromolecules, 50, 7809-7843. https://doi.org/10.1021/acs.macromol.7b01718

Gericke, M., Liebert, T., \& Heinze, T. (2009). Interaction of ionic liquids with polysaccharides, 8-synthesis of cellulose sulfates suitable for polyelectrolyte complex formation. Macromolecular Bioscience, 9, 343-353. https://doi.org/10.1002/ mabi.200800329

Gouveia, A. S., Ventaja, L., Tomé, L. C., \& Marrucho, I. M. (2018). Towards biohydrogen separation using poly(ionic liquid)/ionic liquid composite membranes. Membranes, 8. https://doi.org/10.3390/membranes8040124

Green, O., Grubjesic, S., Lee, S., \& Firestone, M. A. (2009). The design of polymeric ionic liquids for the preparation of functional materials. Polymer Reviews, 49, 339-360. https://doi.org/10.1080/15583720903291116

Guo, Z., Qu, Z., Wu, H., Zhao, R., Wu, Y., Liu, Y., et al. (2020). Polymer electrolyte membranes with hybrid cluster network for efficient $\mathrm{CO} 2 / \mathrm{CH} 4$ separation. ACS Sustainable Chemistry \& Engineering, 8, 6815-6825. https://doi.org/10.1021/ acssuschemeng.0c01709

Hermans, S., Dom, E., Mariën, H., Koeckelberghs, G., \& Vankelecom, I. F. (2015). Efficient synthesis of interfacially polymerized membranes for solvent resistant nanofiltration. Journal of Membrane Science, 476, 356-363. https://doi.org/10.1016/ j.memsci.2014.11.046

Hirokawa, T., Kimura, K., Ohno, K., \& Murata, M. (1980). Vibrational spectra of piperidine, pyrrolidine, morpholine, and their n-methyl derivatives adsorbed on aerosil silica. Spectrochimica Acta Part A: Molecular Spectroscopy, 36, 329-332. https://doi.org/10.1016/0584-8539(80)80138-3

Ho, W., \& Dalrymple, D. (1994). Facilitated transport of olefins in $\mathrm{Ag}^{+}$-containing polymer membranes. Journal of Membrane Science, 91, 13-25. https://doi.org/ 10.1016/0376-7388(94)00008-5

Holda, A. K., \& Vankelecom, I. F. J. (2015). Understanding and guiding the phase inversion process for synthesis of solvent resistant nanofiltration membranes. Journal of Applied Polymer Science, 132, 1-17. https://doi.org/10.1002/app.42130

Hospido, A., \& Rodríguez, H. (2019). Life cycle assessment (LCA) of ionic liquids. Encyclopedia of Ionic Liquids, 1-9. https://doi,org/10.1007/978-981-10-6739-6 54-1

Joseph, N., Ahmadiannamini, P., Hoogenboom, R., \& Vankelecom, I. F. J. (2014). Layerby-layer preparation of polyelectrolyte multilayer membranes for separation. Polymer Chemistry, 5, 1817-1831. https://doi.org/10.1039/C3PY01262J. arXiv: $1310.8002 \mathrm{v} 1$

Kárászová, M., Zach, B., Petrusová, Z., Červenka, V., Bobák, M., Šyc, M., et al. (2020) Post-combustion carbon capture by membrane separation, Review. Separation and Purification Technology, 238. https://doi.org/10.1016/j.seppur.2019.116448

Khan, A. L., Basu, S., Cano-Odena, A., \& Vankelecom, I. F. (2010). Novel high throughput equipment for membrane-based gas separations. Journal of Membrane Science, 354, 32-39. https://doi.org/10.1016/j.memsci.2010.02.069

Klemm, D., Heinze, T., \& Wagenknecht, W. (1996). Properties of regioselectively substituted anionic cellulose polyelectrolytes. Berichte der Bunsengesellschaft/Physical Chemistry Chemical Physics, 100, 730-733. https://doi.org/10.1002/ bbpc.19961000609

Kujawa, J., Rynkowska, E., Fatyeyeva, K., Knozowska, K., Wolan, A., Dzieszkowski, K., et al. (2019). Preparation and characterization of cellulose acetate propionate films functionalized with reactive ionic liquids. Polymers, 11, 1217. https://doi.org/ 10.3390/polym11071217

Lam, B., Wei, M., Zhu, L., Luo, S., Guo, R., Morisato, A., et al. (2016). Cellulose triacetate doped with ionic liquids for membrane gas separation. Polymer, 89, 1-11. https:// doi.org/10.1016/j.polymer.2016.02.033. http://www.sciencedirect.com/science/ article/pii/S0032386116301136
Lee, S., \& Kim, J. K. (2020). Process-integrated design of a sub-ambient membrane process for $\mathrm{CO} 2$ removal from natural gas power plants. Applied Energy, 260, 114255. https://doi.org/10.1016/j.apenergy.2019.114255

Li, J., Wang, S., Nagai, K., Nakagawa, T., \& Mau, A. W. H. (1998). Effect of polyethyleneglycol (PEG) on gas permeabilities and permselectivities in its cellulose acetate (CA) blend membranes. Journal of Membrane Science, 138, 143-152. https:// doi.org/10.1016/S0376-7388(97)00212-3. http://www.sciencedirect.com/science/ article/pii/S0376738897002123

Lilleby Helberg, R. M., Dai, Z., Ansaloni, L., \& Deng, L. (2020). PVA/PVP blend polymer matrix for hosting carriers in facilitated transport membranes: Synergistic enhancement of $\mathrm{CO}_{2}$ separation performance. Green Energy \& Environment, 5, 59-68. https://doi.org/10.1016/j.gee.2019.10.001

Liskey, C., Liu, C., Hamoy, M., Karns, N., Tran, H., \& Greer, D. W. (2018). Dual layercoated membranes for gas separations. https://patentscope.wipo.int/search/en/detail jsf?docId $=$ US212400602\&tab=NATIONALBIBLIO

Liu, M., Nothling, M. D., Webley, P. A., Fu, Q., \& Qiao, G. G. (2019). Postcombustion carbon capture using thin-film composite membranes. Accounts of Chemical Research, 52, 1905-1914. https://doi.org/10.1021/acs.accounts.9b00111

Liu, Y., Liu, Z., Morisato, A., Bhuwania, N., Chinn, D., \& Koros, W. J. (2020). Natural gas sweetening using a cellulose triacetate hollow fiber membrane illustrating controlled plasticization benefits. Journal of Membrane Science, 601, 117910. https://doi.org/ 10.1016/j.memsci.2020.117910

Lu, H., Kanehashi, S., Scholes, C., \& Kentish, S. (2016). The potential for use of cellulose triacetate membranes in post combustion capture. International Journal of Greenhouse Gas Control, 55, 97-104. https://doi.org/10.1016/j.ijggc.2016.11.002

Maciel, V. G., Wales, D. J., Seferin, M., \& Sans, V. (2019). Environmental performance of 3D-Printing polymerisable ionic liquids. Journal of Cleaner Production, 214, 29-40. https://doi.org/10.1016/j.jclepro.2018.12.241

Magnanelli, E., Wilhelmsen, Ø., Johannessen, E., \& Kjelstrup, S. (2016). Enhancing the understanding of heat and mass transport through a cellulose acetate membrane for CO2 separation. Journal of Membrane Science, 513, 129-139. https://doi.org/ 10.1016/j.memsci.2016.04.021

Mazoniene, E., Joceviciute, S., Kazlauske, J., Niemeyer, B., \& Liesiene, J. (2011). Interaction of cellulose-based cationic polyelectrolytes with mucin. Colloids and Surfaces B: Biointerfaces, 83, 160-164. https://doi.org/10.1016/j. colsurfb.2010.11.022

Merkel, T. C., Lin, H., Wei, X., \& Baker, R. (2010). Power plant post-combustion carbon dioxide capture: An opportunity for membranes. Journal of Membrane Science, 359, 126-139. https://doi.org/10.1016/j.memsci.2009.10.041. http://www.sciencedirec t.com/science/article/pii/S0376738809007832

Morozova, S. M., Shaplov, A. S., Lozinskaya, E. I., Vlasov, P. S., Sardon, H., Mecerreyes, D., et al. (2017). Poly(ionic liquid)-based polyurethanes having imidazolium, ammonium, morpholinium or pyrrolidinium cations. High Performance Polymers, 29, 691-703. https://doi.org/10.1177/0954008317701551

Nellepalli, P., Tomé, L. C., Vijayakrishna, K., \& Marrucho, I. M. (2019). Imidazoliumbased Copoly(Ionic Liquid) membranes for $\mathrm{CO}_{2} / \mathrm{N}_{2}$ separation. Industrial \& Engineering Chemistry Research, 58, 2017-2026. https://doi.org/10.1021/acs. iecr.8b05093

Nikolaeva, D., \& Luis, P. (2020). Top-down polyelectrolytes for membrane-based postcombustion CO2 capture. Molecules, 25, 323. https://doi.org/10.3390/ molecules 25020323

Nikolaeva, D., Azcune, I., Sheridan, E., Sandru, M., Genua, A., Tanczyk, M., et al. (2017). Poly(vinylbenzyl chloride)-based poly(ionic liquids) as membranes for $\mathrm{CO}_{2}$ capture from flue gas. Journal of Materials Chemistry A, 5, 19808-19818. https://doi.org/ 10.1039/C7TA05171A

Nikolaeva, D., Azcune, I., Tanczyk, M., Warmuzinski, K., Jaschik, M., Sandru, M., et al. (2018). The performance of affordable and stable cellulose-based poly-ionic membranes in $\mathrm{CO}_{2} / \mathrm{N}_{2}$ and $\mathrm{CO}_{2} / \mathrm{CH}_{4}$ gas separation. Journal of Membrane Science, 564, 552-561. https://doi.org/10.1016/j.memsci.2018.07.057

Pandey, P. K., Awasthi, A., \& Awasthi, A. (2013). Intermolecular interactions in binary mixtures of 2-Chloroethanol with 2-Dimethylaminoethanol and 2-Diethylaminoethanol at different temperatures. Chemical Physics, 423, 119-126. https://doi.org/ 10.1016/j.chemphys.2013.06.025

Petropoulos, J. (1993). Mechanisms and theories for sorption and diffusion of gases in polymers. Polymeric gas separation membranes (pp. 17 82). CRC Press.

Pinkert, A., Marsh, K. N., Pang, S., \& Staiger, M. P. (2009). Ionic liquids and their interaction with cellulose. Chemical Reviews, 109, 6712-6728. https://doi.org/ $10.1021 /$ cr9001947

Pluth, M. D., Fiedler, D., Mugridge, J. S., Bergman, R. G., \& Raymond, K. N. (2009). Encapsulation and characterization of proton-bound amine homodimers in a watersoluble, selfassembled supramolecular host. Proceedings of the National Academy of Sciences United States of America, 106, 10438-10443. https://doi.org/10.1073/ pnas.0809806106

Qu, Z., Wu, H., Zhou, Y., Yang, L., Wu, X., Wu, Y., et al. (2019). Constructing interconnected ionic cluster network in polyelectrolyte membranes for enhanced $\mathrm{CO}$ 2 permeation. Chemical Engineering Science, 199, 275-284. https://doi.org/10.1016/ j.ces.2018.12.050

Quinn, R., Appleby, J., \& Pez, G. (1995). New facilitated transport membranes for the separation of carbon dioxide from hydrogen and methane. Jourzal of Membrane Science, 104, 139-146. https://doi.org/10.1016/0376-7388(95)00021-4

Rathnayake, M. L. L., S. Perera, K., \& P. Vidanapathirana, K. (2020). Past, present and future of ionic liquid based polymer electrolytes. AIMS Energy, 8, 231-251. https:// doi.org/10.3934/energy.2020.2.231

Rynkowska, E., Fatyeyeva, K., \& Kujawski, W. (2018). Application of polymer-based membranes containing ionic liquids in membrane separation processes: A critical 
review. Reviews in Chemical Engineering. 34, 341-363. https://doi.org/10.1515/ revce-2016-0054

Scholes, C. A. (2020). Pilot plants of membrane technology in industry: Challenges and key learnings. Frontiers of Chemical Science and Engineering, 14, 305-316. https://doi. org/10.1007/s11705-019-1860-x

Schuldt, K., Pohlmann, J., Shishatskiy, S., \& Brinkmann, T. (2018). Applicability of polyactive (tm) thin film composite membranes for $\mathrm{CO}_{2}$ separation from $\mathrm{C}_{2} \mathrm{H}_{4}$ containing multi-component gas mixtures at pressures up to $30 \mathrm{bar}$. Membranes, 8 , 1-12. https://doi.org/10.3390/membranes8020027

Shaplov, A. S., Ponkratov, D. O., \& Vygodskii, Y. S. (2016). Poly(ionic liquid)s: Synthesis, properties, and application. Polymer Science Series B, 58, 73-142. https://doi.org/ $10.1134 /$ S156009041602007X

Sigmaaldrich. (2020). FT-NMR for 2-dimethylaminoethanol $\geq 99.5 \%$. https://www.sigmaa ldrich.com/catalog/product/aldrich/471453?\%5C $\% 5 \mathrm{C} \% 5 \mathrm{C} \% 5 \mathrm{C} \% 5 \mathrm{C} \% 5 \mathrm{C} \% 5 \mathrm{C} \%$ 5 Clang $=$ en $\% 5 \mathrm{C} \% 5 \mathrm{C} \% 5 \mathrm{C} \% 5 \mathrm{C} \% 5 \mathrm{C} \% 5 \mathrm{C} \% 5 \mathrm{C}$ \&region $=\mathrm{BE}$.

Simon, N. M., Zanatta, M., Neumann, J., Girard, A. L., Marin, G., Stassen, H., et al. (2018). Cation-Anion- $\mathrm{CO}_{2}$ interactions in Imidazolium-based ionic liquid sorbents. ChemPhysChem, 19, 2879-2884. https://doi.org/10.1002/cphc.201800751

Singh, S. K., \& Savoy, A. W. (2020). Ionic liquids synthesis and applications: An overview. Journal of Molecular Liquids, 297, 112038. https://doi.org/10.1016/j. molliq.2019.112038

Sundell, B. J., Harrigan, D. J., Hayden, S. C., Vaughn, J. T., Guzan, K. A., Lawrence, J. A., et al. (2019). Improved gas transport properties of cellulose acetate via sub-Tg acidcatalyzed silanation. Journal of Membrane Science, 573, 448-454. https://doi.org/ 10.1016/j.memsci.2018.11.077

Teodoro, R. M., Tomé, L. C., Mantione, D., Mecerreyes, D., \& Marrucho, I. M. (2018). Mixing poly(ionic liquid)s and ionic liquids with different cyano anions: Membrane forming ability and $\mathrm{CO}_{2} / \mathrm{N}_{2}$ separation properties. Joumal of Membrane Science, 552, 341-348. https://doi.org/10.1016/j.memsci.2018.02.019

Thornton, A., Freeman, B. D., \& Robeson, L. M. (2020). $\mathrm{CO}_{2} / \mathrm{N}_{2}$ gas separation polymers. https://membrane-australasia.org/msa-activities/polymer-gas-separation-me mbrane-database/.
Tomé, L. C., Gouveia, A. S., Freire, C. S., Mecerreyes, D., \& Marrucho, I. M. (2015). Polymeric ionic liquid-based membranes: Influence of polycation variation on gas transport and $\mathrm{CO}_{2}$ selectivity properties. Journal of Membrane Science, 486, 40-48. https://doi.org/10.1016/j.memsci.2015.03.026

Tomé, L. C., Guerreiro, D. C., Teodoro, R. M., Alves, V. D., \& Marrucho, I. M. (2018). Effect of polymer molecular weight on the physical properties and $\mathrm{CO}_{2} / \mathrm{N}_{2}$ separation of pyrrolidinium-based poly(ionic liquid) membranes. Journal of Membrane Science, 549, 267-274. https://doi.org/10.1016/j.memsci.2017.12.019

Vandezande, P., Gevers, L. E. M., \& Vankelecom, I. F. J. (2008). Solvent resistant nanofiltration: Separating on a molecular level. Chemical Society Reviews, 37, 365-405. https://doi.org/10.1039/B610848M

Vanherck, K., Vandezande, P., Aldea, S. O., \& Vankelecom, I. F. (2008). Cross-linked polyimide membranes for solvent resistant nanofiltration in aprotic solvents. Journal of Membrane Science, 320, 468-476. https://doi.org/10.1016/j.memsci.2008.04.026

Vollas, A., Chouliaras, T., Deimede, V., Ioannides, T., \& Kallitsis, J. (2018). New pyridinium type poly(ionic liquids) as membranes for $\mathrm{CO} 2$ separation. Polymers. 10. https://doi.org/10.3390/polym10080912

Wang, Y., Janout, V., \& Regen, S. L. (2010). Creating Poly(ethylene oxide)-based polyelectrolytes for thin film construction using an ionic linker strategy. Chemistry of Materials. 22, 1285-1287. https://doi.org/10.1021/cm9035488

Zhang, Y., Bakshi, B. R., \& Demessie, E. S. (2008). Life cycle assessment of an ionic liquid versus molecular solvents and their applications. Environmental Science and Technology, 42, 1724-1730. https://doi.org/10.1021/es0713983

Zhang, S. Y., Zhuang, Q., Zhang, M., Wang, H., Gao, Z., Sun, J. K., et al. (2020). Poly (ionic liquid) composites. Chemical Society Reviews, 49, 1726-1755. https://doi.org/ $10.1039 / \mathrm{c} 8 \mathrm{cs} 00938 \mathrm{~d}$

Zou, J., \& Ho, W. W. (2006). $\mathrm{CO}_{2}$-selective polymeric membranes containing amines in crosslinked poly(vinyl alcohol). Joumal of Membrane Science, 286, 310-321. https:// doi.org/10.1016/j.memsci.2006.10.013

Zulfigar, S., Mantione, D., El Tall, O., Ruipérez, F., Sarwar, M. I., Rothenberger, A., et al. (2019). Pyridinium containing amide based polymeric ionic liquids for $\mathrm{CO}_{2} / \mathrm{CH}_{4}$ separation. ACS Sustainable Chemistry \& Engineering, 7, 10241-10247. https://doi. org/10.1021/acssuschemeng. 9b01903 